\title{
Organic Photovoltaics: Technologies and Manufacturing
}

\author{
Yulia Galagan and Ronn Andriessen \\ Holst Centre / TNO \\ Netherlands
}

\section{Introduction}

It is assumed, that the organic electronics industries and organic solar cells in particular, are in the transition stage towards commercialization. The companies and R\&D institutes in this area are moving now from research and development stage to manufacturing. The biggest challenges are how to scale from laboratory to full production, how to select the right tools and processes, and how to use tests and measurements to improve yield and quality. The step from lab-scale to volume production requires adjusting and optimizing of many system aspects, such as: a) deposition techniques and drying conditions, b) substrates, c) ink and solvent systems, d) electrodes and e) dimension of individual cells and modules. Each parameter has its influence on the performance of the final product. In this chapter we discuss a knowledge base concerning the influence of different parameters and process conditions on the performance, cost and lifetime of polymer solar cells.

\section{Deposition techniques}

The first step towards mass production is the choice of deposition techniques which will provide high yield and low cost of production. The key property which makes organic photovoltaics so attractive is the potential of roll-to-roll processing on low cost substrates with standard coating and printing processes. Printing or coating techniques like screen, inkjet, offset, gravure, slot die, spray and others are being established and demonstrated for organic photovoltaic (OPV) devices on lab scale. The next step is to transfer the lab scale know-how to industrial roll-to-roll production. Each technique has certain advantages and disadvantages, which makes a given technique more or less attractive in comparison with others. We will provide a short overview of different deposition techniques and evaluate the applicability of them for industrial manufacturing of different functional layers in organic photovoltaic devices. Different process aspects as line speed, stability of the process, capability, robustness and simplicity of it will be taken into account. However, in addition to process aspects, for successful benchmarking of the different deposition techniques, production aspects are equally important. Uniformity of the deposited layer, layer thickness and overall accuracy as well as excluding possible contamination and destroying the underlayers during printing, are also very important parameters which will determine the final choice. Apart from the process and production aspects, the properties of the ink can also have an influence on the final choice. The inks for each functional layer can be formulated taking into account the requirements of the deposition techniques. At the same 
time the properties of inks such as viscosity, surface tension, solubility, etc. can limit sometimes the usage of certain deposition techniques. The relation between the deposition techniques and the inks will be discussed.

\section{Inks and solvents}

One of the main requirements for the industrial production is a safe and environmentally friendly process. It is well known, that currently the best solvents for organic photoactive materials are chlorobenzene or dichlorobenzene. However, these present barriers to massproduction because of health and environmental issues. That is why, one of the major topics for the technology development is searching for alternative solvents which will provide the appropriate blend morphology and hence, high efficiency of the solar cell devices. The nature of the solvent used for the ink formulation of the OPV blend can have a dramatic effect on the ultimate performance of the solar cell as the solvent system is responsible for good wettability of the photoactive blend on the previous deposited layer, drying and phase separation in the photoactive layer. To provide effective donor-acceptor charge transfer and transport in bulk heterojunction solar cell, the photoactive layer needs to have the right morphology, which means the appropriate domain size, crystallinity and vertical distribution of both components. The choice of solvent or solvent mixture, the conditions of the drying process and the annealing temperature are the most critical factors determining the morphology for a given OPV blend system. The influence of different solvents and solvent mixtures on the performance of the photovoltaic devices will be analyzed. Also, the influence of the solvent on drying and morphology on both lab and roll-to-roll scale will be discussed.

\section{Substrates}

Substitution of glass substrates by flexible foils introduces several changes that will affect the ultimate performance of the OPV devices. The two most important are: (1) the transparency of the substrate and (2) the conductivity of the thin conductive oxide (TCO), which is deposited on the substrate and used as a transparent electrode. The influence of transparency and flexibility on the device performance will be evaluated. Moreover, the conductivity of TCO on flexible substrates will be discussed.

\section{Electrodes}

The strongest motivation for the development of organic photovoltaic (OPV) cell technology is the low cost potential, based on the use of low-cost materials and substrates, the use of nonvacuum and relative low temperature processes $\left(<120^{\circ} \mathrm{C}\right)$ as well as the very high production speeds that can be reached by using roll-to-roll printing and coating techniques. Indium tin oxide (ITO) is one of the main cost consuming elements in present OPV devices due to high cost of indium, the necessity of vacuum deposition and annealing with relative low yields (typically sputtering is used with an average target consumption of about $50-60 \%$ ) and its multi-step patterning. Omitting ITO from the device layout will significantly contribute towards lower production cost. A second argument to omit ITO from OPV devices is mechanical flexibility. The brittle ITO layer can be easily cracked, leading to a decrease in conductivity and, as a result, degradation of the device performance. This fact of course conflicts with the idea of having highly flexible OPV cells. A third argument to omit ITO in OPV applications is its limited conductivity when deposited on plastic foils. With typical sheet resistances of 40-80 Ohm/square, it only allows maximum individual cell widths around 6-10 $\mathrm{mm}$. Larger cell widths will have an immediate negative effect on efficiency. A forth argument to omit ITO in flexible OPV devices relates to the limited annealing temperature that can be 
used on plastic substrates. This causes the higher sheet conductivities as mentioned before compared to $10-20 \mathrm{Ohm} /$ square on glass. But moreover, these results also in a rougher ITO surface compared to ITO on glass. These unwanted roughness and occurring surface peaks will in turn mortgage the reliable deposition of the thin and homogeneous electro-active layers on top of the ITO. Alternative ITO-free electrodes will be presented and evaluated for use in large-area OPV devices. Moreover, methods of producing these ITO-free electrodes by printing and coating methods will be shown.

\section{Size (scaling up)}

The step from lab-scale processing towards industrial manufacturing implies upscaling of single cell sizes and producing modules. What happens when the size of the cell increases; what is the influence of the size on the performance of the OPV devices; what is the maximum size of a cell without substantial efficiency losses; how to minimize efficiency losses during upscaling, and what is the optimum dimension of a module? Answers on these questions will be given in this chapter.

Roll-to-roll production of large area modules: For roll-to-roll production of large area solar cell modules, the correlation between all parameters and the final device performance has to be determined. It is important to find a balance and transfer this knowledge to a roll-to-roll process. First of all, inks with the required properties should be formulated, and the deposition method appropriate for this ink should be chosen. The influence of the deposition method and parameters on the layer properties has to be determined. The influence of drying conditions on the layer properties, such as morphology and uniformity, has to be analyzed. Depending on the deposition method, it is important to determine how the patterning of the layers will be applied. The design and the cell architecture should be optimized. The balance between all parameters can guarantee the successful manufacturing of large area OPV modules.

\section{Roll-to-roll deposition}

The main objectives in the field of Organic Photovoltaics (OPV) are achieving high efficiency, long term stability and low cost. Low cost can be achieved by combining low cost materials with fast roll-to-roll (R2R) manufacturing techniques. Indeed compared with Sibased solar cells, organic solar cells should be less expensive and easier to manufacture, due to the non-vacuum processing, the relatively low temperatures uses during the processing and the possibility of direct patterning during coating or printing. However, in comparison to evaporation processes, solution based processes show quite more challenges in terms of ink formulation, wetting/dewetting, controlling the layer thickness and variations thereof, avoiding intermixing of layers, controlling the self assembly processes, controlling contamination and layer defects and ultimately developing a reliable and robust $24 / 7$ production process.

Benchmarking of deposition techniques for roll-to-roll manufacturing is a complicated process. For the wet chemical deposition of organic semiconductors a large number of deposition techniques can be used. The choice is mainly based on the following factors:

- $\quad$ stability of printing/coating step for the desired materials (viscosity of the ink),

- the capacity of the technique to print/coat the desired feature sizes (lateral resolution, thickness and uniformity),

- $\quad$ throughput of the process. 


\begin{tabular}{lcccc}
\hline Deposition technique & $\begin{array}{c}\text { Roll-to-roll } \\
\text { compatibility }\end{array}$ & $\begin{array}{c}\text { Materials } \\
\text { waste }\end{array}$ & $\begin{array}{c}\text { Layer } \\
\text { thickness } \\
\text { accuracy } \\
\text { (nm scale) }\end{array}$ & $\begin{array}{c}\text { Viscosity } \\
\text { requirements } \\
(\mathrm{mP} \cdot \mathrm{s})\end{array}$ \\
\hline Spin coating & - & very high & very good & $1-40$ \\
Doctor blade coating & - & moderate & good & $1-1000$ \\
Knife Over Roll Coating & + & moderate & moderate & $50-1000$ \\
Metering Rod Coating & + & moderate & moderate & $50-1000$ \\
Slot Die Coating & + & low & very good & $1-10,000$ \\
Curtain Coating & + & low & moderate & $10-500$ \\
Pad printing & + low & moderate & $10-200$ \\
Flexographic printing & + & low & moderate & $15-200$ \\
Gravure Printing & + & low & good & $15-500$ \\
Screen Printing & + & low & moderate & $50-50,000$ \\
Offset printing & + & low & moderate & $100-10,000$ \\
Ink jet Printing & + & low & good & $1-40$ \\
Spray coating & + & high & low & $1-40$ \\
Air Knife Coating & + & moderate & low & $10-200$ \\
Immersion (Dip) Coating & $+/-$ & low & low & $1-200$ \\
Brush coating & - & moderate & low & $1-50$ \\
\hline
\end{tabular}

Table 1. Comparison of different deposition techniques (Brabec et al., 2008; Gamota et al., 2004; Krebs 2009b).

Each layer in an OPV device stack has its own requirements (layer thickness variations, annealing conditions, etc.) but also its own limitations (solubility, solvents, viscosity, surface tension, etc.). This can have an effect on the choice of deposition technique. The choice of the technique should be done individually for the each layer. Although most of the deposition techniques mentioned above have been tested for the deposition of the photoactive layer in organic photovoltaic devices, not all of them are suitable for roll-to-roll mass production. The factors which limit the usage of some deposition techniques are bad compatibility with roll-toroll processing, high materials waste, low speed, high contamination during the processing, low stability and robustness of the process, bad uniformity of the printed layer and minimum thickness of the wet layer. Sometimes the viscosity of the ink limits the usage of given technique for the deposition of a function layer. Typically the viscosity of the ink for a photoactive layer is very low due to the limited solubility of the photo-active compounds. For P3HT/PCBM (Poly3-hexylthiophene (P3HT) and [6,6]-phenyl-C61-butyric acid methyl ester (PCBM)) solutions it is in the range of $1-5 \mathrm{mP} \cdot \mathrm{s}$. The viscosity of PEDOT:PSS (poly $(3,4-$ ethylenedioxythiophene):poly(4-styrene sulphonate) dispersions is typically in the range of 10$30 \mathrm{mP} \cdot \mathrm{s}$. However, also high viscous pastes of PEDOT/PSS are also commercially available with viscosities higher then $50 \mathrm{mP} \cdot \mathrm{s}$. ZnO solutions or dispersions typically also have very low viscosities down to 1-2 $\mathrm{mP} \cdot \mathrm{s}$. These low viscosities already exclude the proper use of techniques like screen printing or offset printing. Silver inks are available both as low viscous inks (for example, ink jet printing) and as pastes, (for example, screen printing). An overview of typical ink viscosity requirements for the different deposition techniques is given in Table 1. The viscosity of the ink is one of the critical factors for the choice of the deposition technology. Viscosity affects the inks flow and how the ink deposits on the substrate. Some techniques require relatively low viscosity, so that each individual printed pixel or cell may merge 
together to form close layer. However, sometimes, too low viscosity can create problems, because it does not allow forming very sharp edges and to print very small features.

The most commonly used deposition technique for the manufacturing of lab scale devices is spin coating, which is not roll-to-roll compatible. However, spin coating is still widely used for studying and understanding the fundamental principles of OPV. Roll-to-roll compatible methods, especially blade and wire bar coatings, are employed as intermediate steps towards real roll-to-roll processing (Schilinsky et al., 2006), (Chang et al., 2009). Roll-to-roll coating and printing of organic semiconductors become a focus of many companies and research groups. Applications based on organic semiconductors, such as organic light emitting diodes and organic photovoltaic devices, have strict requirements to the layer properties, (e.g., thickness, uniformity and overlay accuracy). Many different printing and coating techniques are applied and developed for the deposition of thin layers of organic semiconductors (Krebs, 2009b). For example, jet printing is a well-studied method for the deposition of PEDOT:PSS (Steirer et al., 2009), (Eom et al., 2009), and polymer-fullerene blends (Aernouts et al., 2008; Hoth et al., 2007; Hoth et al., 2008). The advantage of this method is the possibility to deposit patterned layers in one printing step. The challenge is to find appropriate solvent systems for polymer-fullerene blends, which will provide appropriate spreading and wetting of the ink on the substrate and homogeneous drying with the required morphology of the active layer.

Gravure printing, which is widely used for the printing of organic transistors (Kaihovirta et al., 2008; Voigt et al., 2010), has also been applied for the deposition of OPV layers (Ding et al., 2009; Kopola et al., 2011; Kopola et al., 2010; Voigt et al., 2011). The main difficulty in gravure printing is the required viscosity of the ink, which is for most of the OPV blend systems difficult to reach due to the limited solubility of the components. The somewhat higher needed ink viscosity will also partially hamper the leveling process which is required to achieve high homogeneity of the layers after printing and drying.

There are a number of publications on spray coating of photovoltaic inks (Green et al., 2008; Hoth et al., 2009; Ishikawa et al., 2004; Steirer et al., 2009; Vak et al., 2007; Park et al., 2011; Susanna et al., 2011; Girotto et al., 2011). This deposition method is very efficient especially for low viscosity solutions and is less demanding in terms of ink formulation. However, control on layer homogeneity and the current lack of easy-for-use patterning strategies makes it currently somewhat less attractive for roll-to-roll processes.

Pad printing is a rather unconventional method which has been employed in a roll-to-roll process for the fabrication of OPV (Krebs, 2009c). Screen printing has been applied for the deposition of photoactive layers based on MDMO-PPV:C60-PCBM (Shaheen et al., 2001) and MEH-PPV:C60-PCBM (Krebs et al., 2004; Krebs et al., 2007). As well as a complete process for production of flexible large area polymer solar cells entirely using screen printing has been demonstrated (Krebs et al., 2009b). There are many publications where slot die coating was chosen for the deposition of several layers, including active layer, in polymer based solar cells (Blankenburg et al., 2009; Krebs \& Norrman, 2010; Krebs, 2009e; Krebs, 2009a; Krebs, 2009d; Krebs et al., 2009a; Zimmermann et al., 2011). As one of the coating techniques, slot die deposition can provide very thin, uniform, non-patterned layers. One-dimensional patterning is possible by coating stripes which can be used for making OPV modules.

Each deposition technique has advantages and disadvantages. The biggest disadvantage of coating techniques is a requirement of post patterning, which is not a problem for printing methods. Coating techniques can provide very thin uniform layers, but patterning in most of the cases should be done in a separate process step which will add costs to the production process. The typical post-patterned methods are laser ablation, photolithography (Lim et al., 
2009), plasma etching (Colsmann et al., 2009) or solvent etching. Patterning can also be applied in one process step together with coating by self assembled coating based on wetting and dewetting process. However, printing, which typically can provide any feature or structure, can not compete in layer uniformity with coating techniques.

The choice of the deposition technique depends very much on the characteristics of the methods and the criteria which made these methods attractive. The main criteria of selection are based on:

- materials aspects such as viscosity, surface tension of the ink and surface energy of the substrate;

- products aspects, which include uniformity of the layer, layer thickness, possibility of patterning;

- $\quad$ process aspects, such as, roll-to-roll compatibility, speed of the process, stability of the process, capability, robustness and simplicity of the process.

However, selection of a technique at this point of technology development very much depends on how this technique fit with the know-how of organization, their experience and availability of equipment. Collaborations and partnerships very often make some of the deposition techniques more attractive. The market attractiveness also has a lot of influence on the selection of the deposition method. Moreover, the possibility to generate sustainable IP position, publications and innovation sometimes is a leading factor for the selection. The cost of the equipment and total cost of the process are the final criteria of the selection. The satisfaction of the aforementioned is a first step for successful selection, so that technological processes developed with the selected technique can be readily commercialized.

\subsection{Roll-to-roll coated PEDOT:PSS and photoactive layers (am example)}

The example of successful roll-to-roll coating of the hole transport layer (PEDOT:PSS) and the photoactive layer (P3HT/PCBM) by slot die is illustrated by (Galagan et al., 2011b). The PEDOT:PSS (OrgaconTM) formulation for slot die coating was delivered by Agfa-Gevaert. A thin layer of PEDOT:PSS was deposited with a speed of $10 \mathrm{~m} / \mathrm{min}$ and dried with the same speed at $110^{\circ} \mathrm{C}$. The thickness of the dry layers was about $110 \mathrm{~nm}$ and illustrates high uniformity. The layer thickness variation was within $\pm 2 \%$. The thickness and uniformity of the layer was checked by ellipsometry. The results of these measurements are shown in Fig. 1.

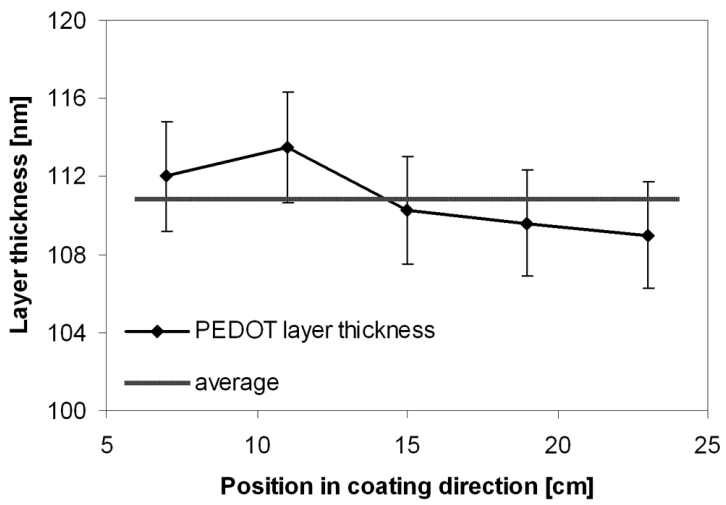

Fig. 1. Layer thickness of roll-to-roll slot die coated PEDOR:PSS layer, measured every $5 \mathrm{~cm}$ in coating direction (reproduced with permission from (Galagan et al., 2011b), Copyright 2010, Elsevier B.V.). 
The photoactive layer was coated from o-xylene solution. The concentration of the inks was $10 \mathrm{mg} / \mathrm{ml}$. The layer was coated and dried with a speed of $10 \mathrm{~m} / \mathrm{min}$. The drying has been performed at $90^{\circ} \mathrm{C}$ during 30 seconds. Fig. 2 illustrates the roll of the PET foil with slot die coated PEDOT:PSS and OPV layers.
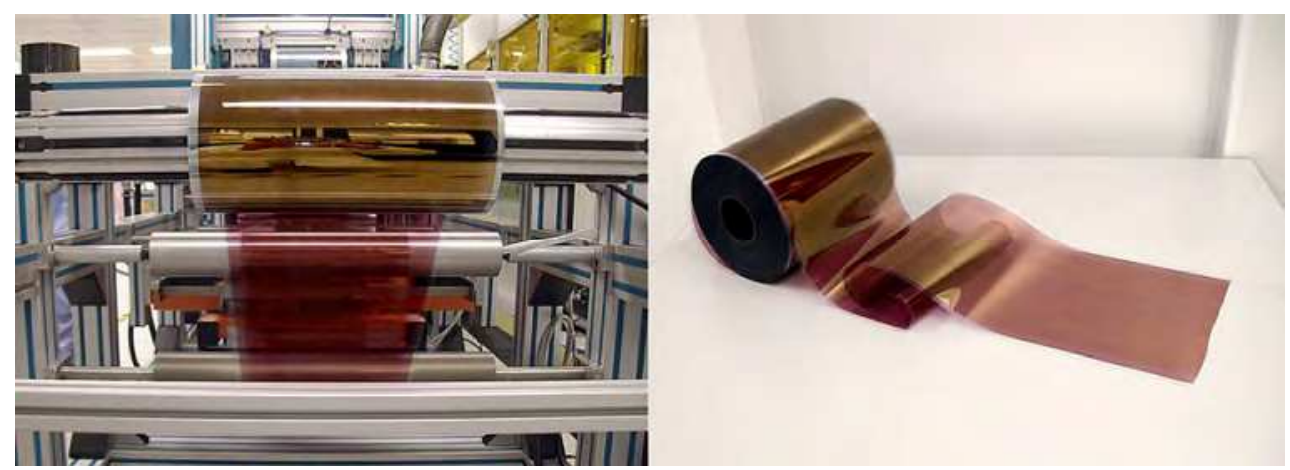

Fig. 2. Roll of the PET foil with slot die coated PEDOT and photoactive layers (reproduced with permission from (Galagan et al., 2011b), Copyright 2010, Elsevier B.V.).

\section{Substrates}

The substrates for OPV devices must satisfy numerous requirements, such as: optical quality of transparency to let light reach the photoactive layer; substrate smoothness in the nanometer range to provide a surface that will promote high-quality deposition of subsequent layers and prevent the penetration of potential substrate spikes or irregularities into the device layers; the ability to support processing at high enough temperatures; good dimensional stability; good resistance to any chemicals used during processing; low water absorption.

\section{Optical properties}

Transparency is one of the main characteristics of substrates. Both transparent and nontransparent substrates are suitable for the manufacturing of organic solar cells. However, non transparent substrates constrain some device architectures. The usage of nontransparent substrates requires transparent top electrodes with transparent top barrier layers. Devices on transparent substrates can have their transparent electrode either on top or on the bottom side of the devices or even on both sides, in case of semi-transparent solar cells. However, in most cases, the transparent substrate is combined with a transparent electrode. Such device architecture requires high optical transparency of the electrode as well as the substrate. Also the barrier (directly attached to the substrate or laminated afterwards) should have high optical transparency. In addition, substrates for OPV devices should have low birefringence.

\section{Surface roughness}

Thin film devices are very sensitive to surface roughness. High roughness structures over short distances must be avoided, as it can create shorts in the devices. However, an intermediate roughness over long distance is acceptable. Standard metal substrates usually are rough on both scales, while plastic substrates may be rough only over long distances. 


\section{Thermal and thermo-mechanical properties}

Some processes of solar cells fabrication such as drying annealing and thermal sintering require applying of high temperatures. It is important that maximum fabrication process temperature must be lower then the glass transition temperature of the substrate polymer.

\section{Dimensional stability}

Glass substrates have very high dimensional stability. But conventional processing on glass substrates can not be directly transferred on plastic. The thermal contraction mismatch between the substrates and the deposited device film and built-in stresses in these films lead to curving and changing in the in-plane dimension of the substrates. This change causes misalignment between the device layers. Plastic substrates will also change size on exposure to moisture. The first defense against these changes is the selection of substrates with low water absorption and low coefficients of hydroscopic expansion. Appropriate substrate selection and heat stabilization techniques can significantly reduce the size of changes, but they can not eliminate them completely.

\section{Mechanical properties}

A high elastic modulus makes the substrate stiff, and a hard surface support the device layer under impact.

\section{Chemical properties}

The substrates should not release contaminants and should be inert against process chemicals.

\section{Barrier properties}

Barrier properties of the substrates against permeation of atmospheric gasses such as water and oxygen can be the biggest advantage of the substrates.

\section{Electrical properties}

Some substrates, such as metal foil or ITO coated plastic foils are conductive. These conductive substrates may serve as an electrode in solar cell architecture.

The main substrates used for the manufacturing of organic photovoltaic devices are glass, plastic and metal foil. The properties of typical substrate materials are given in Table 2.

\begin{tabular}{lccc}
\hline Property & Glass & PEN & Stainless steel \\
\hline Weight, $\mathrm{mg} / \mathrm{m}^{2}$ (for $100-\mu \mathrm{m}$-thik film) & 220 & 120 & 800 \\
Transmission in the visible range $(\%)$ & 92 & 90 & 0 \\
Maximum process temperature $\left({ }^{\circ} \mathrm{C}\right)$ & 600 & 180 & $>600$ \\
TCE $\left(\mathrm{ppm} /{ }^{\circ} \mathrm{C}\right)$ & 5 & 16 & 10 \\
Elastic modulus $(\mathrm{Gpa})$ & 70 & 5 & 200 \\
Permeability for oxygen and moisture & No & Yes & No \\
Coefficient of hydrolytic expansion & 0 & 11 & 0 \\
(ppm/\% $/ \mathrm{RH})$ & & & \\
Planarization necessary & No & No & Yes \\
Electrical conductivity & None & None & High \\
Thermal conductivity & 1 & 0.1 & 16 \\
\hline
\end{tabular}

Table 2. Comparison of PEN, stainless steel and glass substrates (Lawrence et al., 2004). 


\subsection{Metal foil substrates}

Metal foil substrates offer the advantages of higher process temperature capability, dimensional stability and excellent barrier properties for oxygen and water. The disadvantages and limitations of the metal foil substrates include non-transparency and surface roughness. However, non-transparent metal foils can be successfully used in some of the device architectures, where illumination of the OPV devices occurs from the top side. The smoothness of the metal substrates can be increased by polishing or by applying additional planarization layers. The planarization layer can be organic, inorganic, or a combination. With high content of organic components, thicker layer of planarization material can be applied without forming cracks and a very smooth surface can be achieved. It is very important for OPV devices, because the electro-active layers are very thin and the chance to have shorts in the devices is much higher with rougher surfaces.

The conductivity of metal substrates can be considered both as an advantage and disadvantage. Sometimes the metal substrate can be served as back contact, but very often the conductive property of the metal substrate is not used. In such case conducting substrates are completely insulated from OPV device by an additional planarizaton layer.

Stainless steel has been most commonly used in research because of its high resistance to corrosion and process chemicals, and its long record of application in amorphous silicon solar cells. Stainless steel substrates can tolerate process temperature as high as $1000^{\circ} \mathrm{C}$. These substrates are dimensionally stable and have excellent barrier properties against water and oxygen. Generally, stainless steel substrates are more durable then plastic substrates.

\subsection{Flexible plastic substrates}

Polymer foil substrates are highly flexible, can be inexpensive and are roll-to-roll compatible. Transparent plastic substrates have the advantage of being compatible with any organic solar cell architecture. The most common plastic substrates for fabrication OPV devices are polyethylene terephthalate (PET), polyethylene naphthalate (PEN), polycarbonate (PC), polyethersulfone (PES) and polyimide (PI). While polyimide (e.g., Kapton ${ }^{\circledR}$ from DuPont) absorbs in the visible region (has yellow colour), which makes it not suitable for all device architectures. However, the advantage of this plastic substrate is its high process temperature capability $\left(>350^{\circ} \mathrm{C}\right)$, while other plastic substrates have limited process temperature capabilities, as shown in Table 3.

\begin{tabular}{lccccc}
\hline Property & $\begin{array}{c}\text { PET } \\
\text { Melinex }\end{array}$ & $\begin{array}{c}\text { PEN } \\
\text { Teonex }\end{array}$ & $\begin{array}{c}\text { PC } \\
\text { Lexan }\end{array}$ & $\begin{array}{c}\text { PES } \\
\text { Sumilite }\end{array}$ & $\begin{array}{c}\text { PI } \\
\text { Kapton }\end{array}$ \\
\hline $\mathrm{Tg}^{\circ}{ }^{\circ} \mathrm{C}$ & 78 & 121 & 150 & 223 & 410 \\
$\mathrm{CTE}^{*}\left(-55\right.$ to $\left.85{ }^{\circ} \mathrm{C}\right)$ & 15 & 13 & $60-70$ & 54 & $30-60$ \\
Transmission $(400-700 \mathrm{~nm}), \%$ & 89 & 87 & 90 & 90 & yellow \\
Moisture absorption, \% & 0.14 & 0.14 & 0.4 & 1.4 & 1.8 \\
Young's modulus, Gpa & 5.3 & 6.1 & 1.7 & 2.2 & 2.5 \\
Tensile strength, Mpa & 225 & 275 & - & 83 & 231 \\
Density, gcm ${ }^{-3}$ & 1.4 & 1.36 & 1.2 & 1.37 & 1.43 \\
Refractive index & 1.66 & $1.5-1.75$ & 1.58 & 1.66 & - \\
Birefringence, nm & 46 & - & 14 & 13 & - \\
\hline
\end{tabular}

Table 3. Properties of plastic substrates (Lawrence et al., 2004) (* - coefficient of thermal expansion). 
Another disadvantage of plastic substrates is the lack of dimensional stability during processing at elevated temperatures. There are no polymeric substrates which meet the extremely demanding requirements for low moister and water permeability for OPV application. The typical water and oxygen permeation rates of flexible plastic substrates are $1-10 \mathrm{~g} / \mathrm{m}^{2} /$ day and $1-10 \mathrm{~cm}^{3} / \mathrm{m}^{2} /$ day, respectively, instead of typically required for organic electronic devices $10^{-3}-10^{-6} \mathrm{~g} / \mathrm{m}^{2} /$ day and $10^{-3}-10^{-5} \mathrm{~cm}^{3} / \mathrm{m}^{2} /$ day. Ideal plastic substrates required additional barrier layer coatings. Barrier coatings can reduce the absorption and permeability of the atmospheric gasses, can raise the resistance to process chemicals, can strengthen the adhesion of the device layers, and can reduce the surface roughness. Despite some of these disadvantages, plastic substrates have a lower cost potential compared to the metal foil substrates. Table 3 summarizes the properties of the most common substrates which can be used in organic solar cells manufacturing.

\subsection{Glass substrates}

Plastic substrates offer the property of flexibility that is very important for roll-to-roll manufacturing. But at the same time, there are a lot of applications for solar cells where rigid substrate can be used - first of all, in solar windows. In this case a glass substrate makes a logical choice. Glass has also many advantages over plastic substrates. Glass is highly transparent over the total visible spectrum, it has a high homogeneity of the refractive index and it shows a high UV resistance. Compared with plastic substrates, glass has more advanced thermal properties like high temperature stability, high dimensional stability and a low thermal expansion coefficient. Additionally, glass has a high chemical resistance and excellent barrier properties against water and oxygen. Good barrier properties of the glass substrate can probably significantly decrease the cost of the solar cells, as in such case an extra barrier layer will not required. Moreover, the good barrier properties of the glass can improve the lifetime of the solar cells. Due to the high mechanical stability, glass substrates have also advantage in high scratch resistance.

\section{Inks and solvents}

The most widely studied materials for the photoactive layer for OPV devices are P3HT and PCBM, which are typically blended in a solvent or solvent mixture. The optimal solvents to reach good solubility and stability and ultimately high device efficiencies for this mixture are o-dichlorobenzene and chlorobenzene. However, chlorinated aromatic solvents can not be used in mass-production due to health and environmental reasons. That is why, the first topic for the technology development is searching for alternative lower-toxicity solvents which will provide appropriate morphology and hence, high efficiencies of the solar cell devices. The choice of solvent for OPV blend is one of the major factors which have influence on the performance of the solar cell. Indeed, the solvent is responsible for appropriate wettability of the photoactive blend on the previously deposited layer, drying behaviour and phase separation in the photoactive layer. To provide effective donoracceptor charge transfer and transport in bulk heterojunction solar cells, the photoactive layer has to demonstrate the right morphology, which means appropriate domain size, crystallinity and vertical distribution of both components. The choice of solvent, drying conditions and annealing temperature and time are the most critical factors determining the final morphology. The effect of morphology can be described by the formation of an effective network between donor and acceptor which creates effective routes for separated charge transport. The phase separation in P3HT/PCBM systems has been well studied in 
several solvent systems (Baek et al., 2009; Berson et al., 2007; Jang et al., 2009; Janssen et al., 2007; Kawano et al., 2009; Kim et al., 2011; He et al., 2011). The properties of the solvents, such as boiling point, vapor pressure, solubility and surface tension have a considerable impact on the final morphology of the photoactive layer. There are several publications where alternative more environmentally friendly solvents have been used for the deposition of the photo-active layer (Hoth et al., 2007; Hoth et al., 2009; Zhao et al., 2009). The use of solely toluene as a solvent demonstrated to yield a non-preferable morphology for P3HT/PCBM blend (Hoppe \& Sariciftci, 2006). Xylene is also a well studied alternative solvent for this system and the solubility of both P3HT and PCBM in o-xylene is better in comparison with toluene. Moreover, the boiling point and viscosity of o-xylene are very close to the values of chlorobenzene (Table 4). For all these reasons we choose o-xylene as a solvent for this study.

\begin{tabular}{lccccc}
\hline Solvent & $\begin{array}{c}\text { Vapor } \\
\text { pressure } \\
{[\mathrm{mm} \mathrm{Hg}]}\end{array}$ & $\begin{array}{c}\text { Boiling } \\
\text { point } \\
{\left[{ }^{\circ} \mathrm{C}\right]}\end{array}$ & $\begin{array}{c}\text { Surface } \\
\text { tension } \\
{\left[\text { dynes cm }{ }^{-1}\right]}\end{array}$ & $\begin{array}{c}\text { Viscosity } \\
{[\mathrm{mPa} \mathrm{s}]}\end{array}$ & $\begin{array}{c}\text { Health hazards } \\
\text { TLV-TWA } \\
{[\mathrm{ppm}]}\end{array}$ \\
\hline Chlorobenzene & $11.80\left(25^{\circ} \mathrm{C}\right)$ & 132 & 33.0 & $0.80\left(20^{\circ} \mathrm{C}\right)$ & 10 \\
o-Xylene & $5.10\left(20^{\circ} \mathrm{C}\right)$ & 144 & 28.7 & $0.76\left(25^{\circ} \mathrm{C}\right)$ & 100 \\
\hline
\end{tabular}

Table 4. Solvent properties (Galagan et al. 2011b).

Bulk heterojunction solar cells have been prepared by spin coating of PEDOT and OPV layers on ITO coated glass substrate. A LiF/Al top electrode was vacuum evaporated. The OPV blend consists of a mixture of P3HT (purchased from Merck, Mw $=20050 \mathrm{~g} / \mathrm{mol}$ ) and PCBM (purchased from Solenne) in a ratio of 1:1. The photoactive layer was spin coated from chlorobenzene as comparison and o-xylene solutions. The concentration of tP3HT was $15 \mathrm{mg} / \mathrm{ml}$.

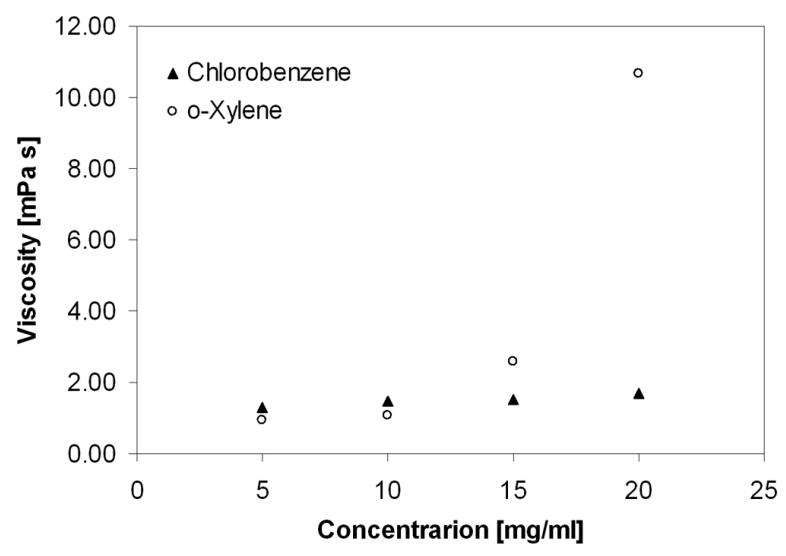

Fig. 3. Viscosity of the P3HT:[C60]PCBM (1:1) mixture in chlorobenzene and o-xylene as function of P3HT concentration (reproduced with permission from (Galagan et al., 2011b), Copyright 2010, Elsevier B.V.).

The OPV ink was processed in ambient conditions. The solutions were stirred for 14 hours at $70^{\circ} \mathrm{C}$ and subsequently cooled down to room temperature and processed within $30 \mathrm{~min}$. 
Upon cooling aggregation and gelation is often observed due to limited solubility of P3HT at room temperature. The time of gelation strongly depends on the molecular weight of the polymer (Koppe et al., 2009) and the solubility of the polymer in a certain solvent. The gelation of the P3HT:[C60]PCBM mixture, indicated by an increase in the viscosity of the mixture is shown in Fig. 3. The viscosity was measured after $30 \mathrm{~min}$ when the solution was cooled down. o-Xylene solution of P3HT/PCBM mixture shows up a high tendency for gelation when the concentration of the solution increases. P3HT in o-xylene solution shows a rather fast gel formation at room temperature, causing particles, film defects and the reduction of solution's shelf lifetime (Koppe et al., 2009; Malik et al., 2001).

AFM topographic images of a P3HT/PCBM layer, deposited from o-xylene on top of Pedot coated glass substrates, demonstrate higher roughness in comparison with chlorobenzene as-casted layer, as shown in Fig. 4 (a and c). The observed higher roughness of o-xylene deposited layer corresponds probably with the polymer aggregates which were formed in the solution. UV-Vis absorption spectra of as-casted P3HT/PSBM layers deposited from oxylene show a blue-shift in comparison with the same layer deposited from chlorobenzene (Fig. 5, a). The shift of the $\Pi-\Pi^{*}$ transition absorption peaks to higher energy indicates an increasing density of conformational defects, equivalent to non-planarity, and causes loss in conjugation (Hotta et al., 1987; Inganäs et al., 1988). The observed red-shift of the absorption maximum in chlorobenzene deposited layers indicates a better crystallinity of P3HT.

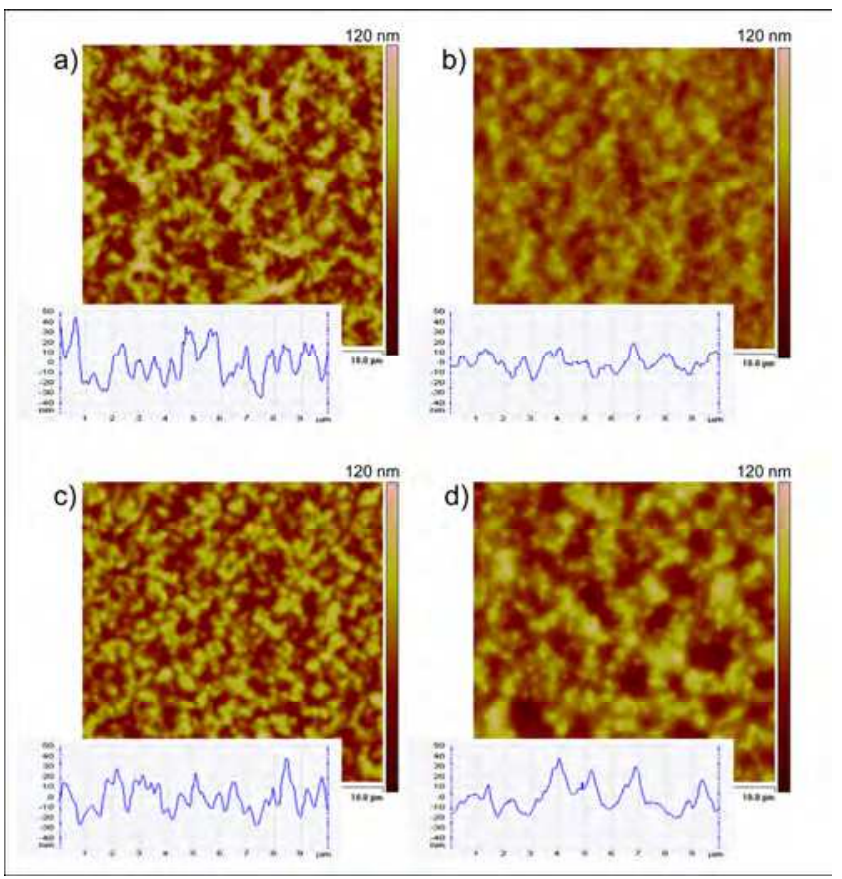

Fig. 4. AFM images of OPV layer deposited from a) o-xylene without annealing, b) o-xylene annealed during $10 \mathrm{~min}$ at $110^{\circ} \mathrm{C}, \mathrm{c}$ ) chlorobenzene without annealing and d) chlorobenzene annealed during $10 \mathrm{~min}$ at $110^{\circ} \mathrm{C}$ (reproduced with permission from (Galagan et al., 2011b), Copyright 2010, Elsevier B.V.). The measurements were performed with a VEECO Dimension 3100 scanning probe microscope, using Si probes in tapping mode. 
Thermal annealing at $110^{\circ} \mathrm{C}$ during $10 \mathrm{~min}$ increases the crystallinity of the deposited photoactive layers both deposited from chlorobenzene or o-xylene. This is indicated in the UV-Vis spectra (Fig. 5, a). The topology of the chlorobenzene deposited layer after annealing shows an increase of roughness that typically also can be attributed to an increase in crystallinity. However, the roughness of the o-xylene deposited layer decreases after annealing. This might be caused by a (partial) destruction of amorphous aggregates.

The solar cells, made from both chlorobenzene and o-xylene, illustrate a clear increase of the performance after thermal annealing (Table 5). The thickness of the photoactive layers has been optimized to $200 \mathrm{~nm}$. J-V curves of the devices after thermal annealing are given in (Fig. 5, b). Current-voltage curves were measured using simulated AM 1.5 global solar irradiation $\left(100 \mathrm{~mW} / \mathrm{cm}^{2}\right)$, using a xenon-lamp-based solar simulator Oriel (LS0104) 150W. The lower current in the device produced from o-xylene compared to chlorobenzene after annealing can probably be explained by a difference in the morphology of photoactive layer. Morphology difference is mainly caused due to differences in solvent properties such as boiling point, vapor pressure, viscosity, surface tension and polarity. Another important parameter is solubility which can lead to the formation of aggregates already in the solution. Aggregation and gelation can have a big influence on the final morphology and device performance.
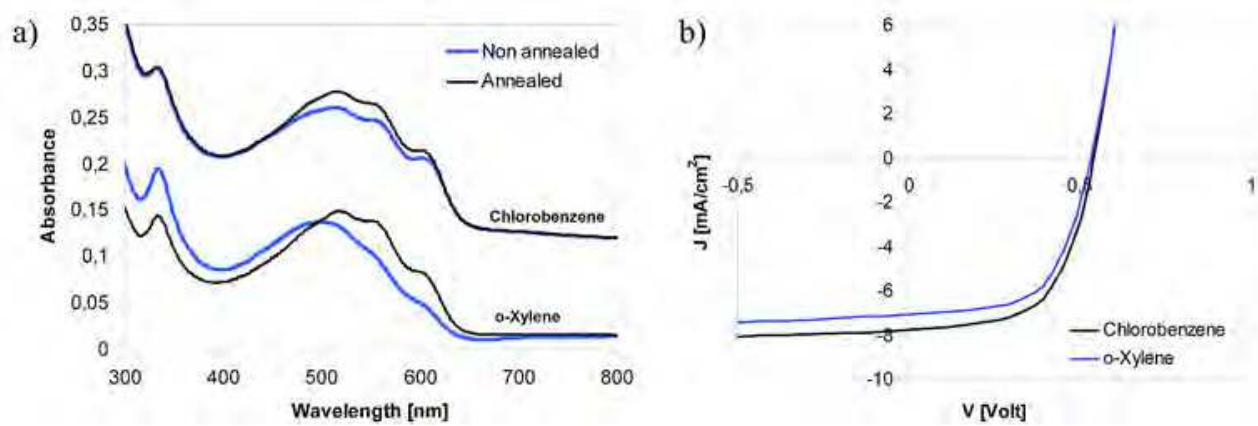

Fig. 5. a - UV-Vis spectra of P3HT/PCBM layers deposited from chlorobenzene and o-xylene before and after thermal annealing. The thicknesses of the layers are $200 \mathrm{~nm}$ (reproduced from (Galagan et al., 2011b) with permission); b- J-V curves of OPV devices, deposited from chlorobenzene and o-xylene solutions. The active area of the devices is $0.09 \mathrm{~cm}^{2}$ (reproduced with permission from (Galagan et al., 2011b), Copyright 2010, Elsevier B.V.).

\begin{tabular}{lcccc}
\hline Device (solvent, annealing) & $\begin{array}{c}\text { Jsc } \\
{\left[\mathrm{mA} / \mathrm{cm}^{2}\right]}\end{array}$ & Voc [Volt] & FF & ๆ [\%] \\
\hline Chlorobenzene, non annealed & 3.64 & 0.572 & 0.296 & 0.62 \\
Chlorobenzene, annealed & 7.75 & 0.546 & 0.572 & 2.42 \\
o-Xylene, non annealed & 4.71 & 0.507 & 0.332 & 0.79 \\
o-Xylene, annealed & 7.05 & 0.535 & 0.581 & 2.19 \\
\hline
\end{tabular}

Table 5. The characteristics of photovoltaic devices, produced from different solvents, with and without thermal annealing $\left(110^{\circ} \mathrm{C}\right.$ during 10 minutes) (Galagan et al., 2011b). 


\section{Scaling up}

Scaling up of the active area of the solar cell devices typically leads to efficiency losses (AlIbrahim et al., 2004; Gupta et al., 2008; Lungenschmied et al., 2007; Manor et al., 2011). The trend of the losses strongly depends on the sheet resistance of the electrode. Thus, scaling up of the square shaped active areas from $0.09 \mathrm{~cm}^{2}$ to $6 \mathrm{~cm}^{2}$, results in about $20 \%$ efficiency loss, for ITO-based devices prepared on glass substrates (Table 6). The JV curves of the devices are shown on Fig. 6.

\begin{tabular}{lcccc}
\hline Active area, $\mathrm{cm}^{2}(\mathrm{~cm} \times \mathrm{cm})$ & Jsc $\left[\mathrm{mA} / \mathrm{cm}^{2}\right]$ & Voc [Volt] & FF & $\eta[\%]$ \\
\hline $0.09(0.3 \times 0.3)$ & 7.75 & 0.546 & 0.572 & 2.42 \\
$6(2 \times 3)$ & 7.46 & 0.530 & 0.478 & 1.89 \\
\hline
\end{tabular}

Table 6 . The characteristics of photovoltaic devices with different active areas (Galagan et al., 2011b). Devices produced from chlorobenzene solution. Solar cell parameters are corresponding to Fig. 6.

The efficiency of the devices shows a rapid decay upon increasing the width of the solar cells (Lungenschmied et al., 2007). By adding on one side of a cell a charge collector or busbar for the anode and on the opposite side a charge collector or busbar for the cathode only the width of the electrode is relevant for the resulting device efficiency. To keep the resistivity losses in the electrode as small as possible, the width has to be narrow with the contacts taken on the long side. Based on the experimental findings (Al-Ibrahim et al., 2004; Gupta et al., 2008; Lungenschmied et al., 2007) and theoretical modeling (Lungenschmied et al., 2007), it was illustrated that significant loses in the efficiency of the solar cells are expected when the width of the cell is higher than $1 \mathrm{~cm}$. The effective coverage of a large area is only possible by interconnecting several devices.

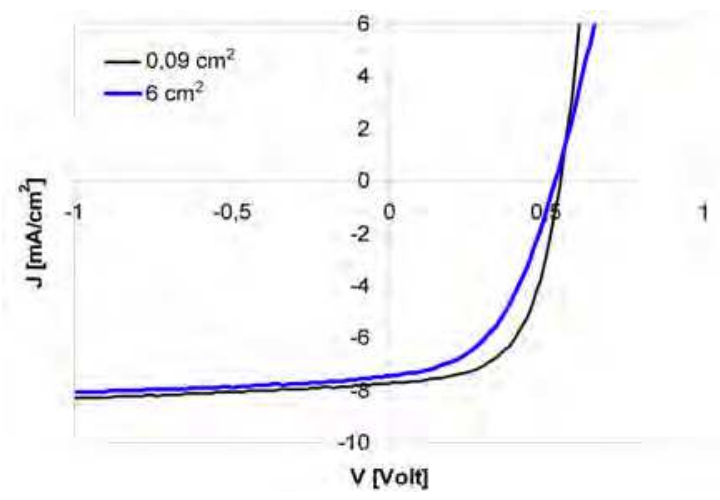

Fig. 6. J-V curves of OPV devices, deposited from chlorobenzene solution with different sizes of active area: $0.09 \mathrm{~cm}^{2}$ and $6 \mathrm{~cm}^{2}$ (reproduced with permission from (Galagan et al., 2011b), Copyright 2010, Elsevier B.V.).

\section{Electrodes}

The main attractiveness of organic solar cells is the low cost potential due to roll-to-roll solution based fabrication. However, currently fabrication of the (transparent) electrodes is 
usually done by vacuum deposition. Combination of printed organic layers and vacuum deposited electrodes will increase the cost of such OPV devices. Thus, to reach the goal of low-cost manufacturing, all layers in OPV devices should be solution processed. There are a lot of publications where all-solution processed OPV devices with inverted structures have been reported (Krebs et al., 2011; Ming-Yi et al., 2010; Hagemann et al., 2008; Hsiao et al., 2009). But in these publications only the top electrode is printed. The bottom electrode is still ITO, which is deposited in vacuum. ITO-free OPV devices with solution processed top electrode has been illustrated in (Manceau et al., 2011; Krebs, 2009e), but in these cases, the bottom electrode is a metal layer deposited in vacuum. All-solution processed polymer solar cells free from ITO and vacuum coating steps have been reported (Krebs, 2009a), where the bottom electrode is a solid layer of printed Ag and $\mathrm{ZnO}$. Printing of a top electrode in a conventional device configuration is less studied, however, successful preparation of solar cells with nano-scale $\mathrm{ZnO}$ as a buffer layer and inkjet printed silver cathode have been described (Eom et al., 2008). Roll-to-roll processing of solution processable electrodes will significantly contribute towards low-cost manufacturing of OPV devices.

\subsection{ITO electrode}

The efficiency of a solar cell depends on the electrode dimensions and its sheet resistance. Typically, the sheet resistance of ITO/glass substrate is 10-15 $\Omega / \square$, while the sheet resistance of ITO on PET substrate is around $60 \Omega / \square$. A rapid decay of the efficiency was shown upon increasing the width of the solar cell (Fig. 7, a). Moreover, a much faster decay was observed in case of a foil substrate with a higher sheet resistance. Thus, the efficiency of solar cells on plastic substrate drops down almost two times in comparison with the cell on glass substrate, for the devices with an active area of $2 \times 2 \mathrm{~cm}^{2}$. The series resistance induced by the sheet resistance of the electrode can dramatically reduce the charge collection in the device. The J-V curves of the devices on glass and foil substrate are shown in Fig. 7, b.

a)

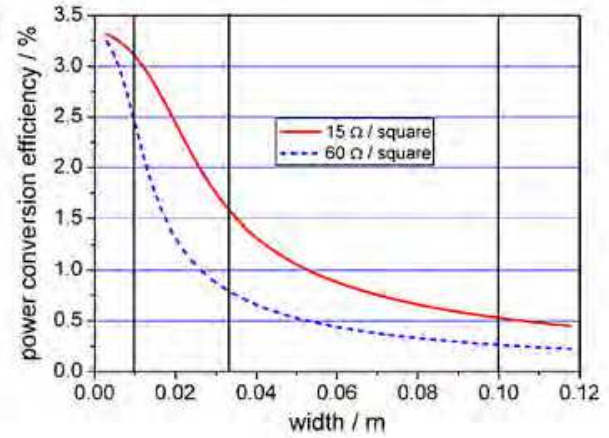

b)

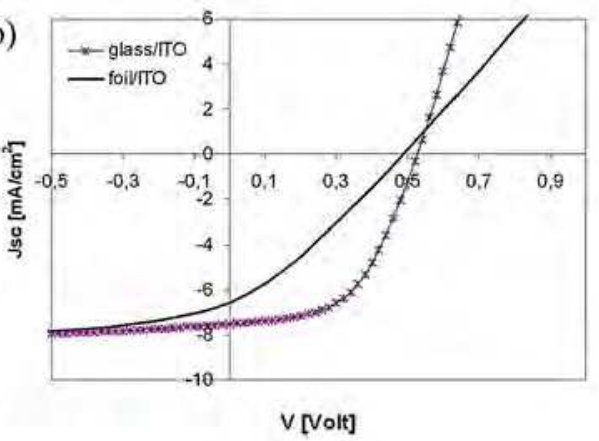

Fig. 7. a - Calculated theoretical power conversion efficiency of a P3HT:PCBM-based single rectangular organic solar cell as a function of the width of the electrode. Two cases are shown, an ITO sheet resistance of $15 \mathrm{Ohm} /$ square (solid line) and $60 \mathrm{Ohm} /$ square (dashed line) (reproduced with permission from (Lungenschmied et al., 2007), Copyright 2006, Elsevier B.V.); $\mathrm{b}-\mathrm{J}-\mathrm{V}$ curves of OPV devices with active area of $4 \mathrm{~cm}^{2}$, prepared on glass and foil substrate. The sheet resistance of ITO on glass is $13 \mathrm{Ohm} /$ square, and on foil is 60 Ohm/square (reproduced with permission from (Galagan et al., 2011b), Copyright 2010, Elsevier B.V.). 
Within realistic ranges of substrate conductivities (15-60 $\Omega / \square)$, the overall device efficiency heavily depends on the width of the electrode. To keep the resistivity losses in the electrode as small as possible, the width has to be narrow with the contacts taken on the long side. This minimizes the distance where the charges, extracted from the active layer, have to travel in the resistive ITO electrode.

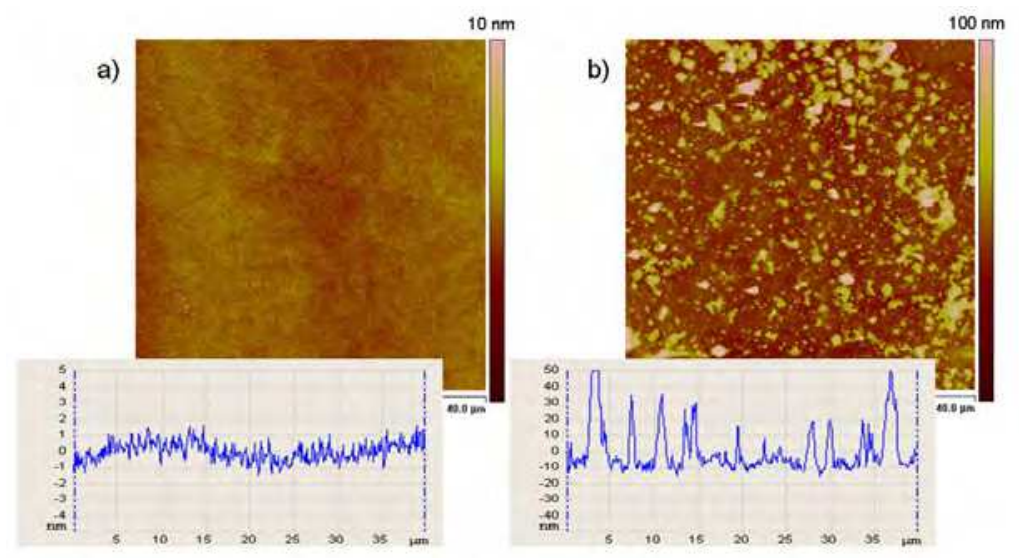

Fig. 8. AFM topology image of (a) ITO coated glass and (b) ITO coated PET foil (reproduced with permission from (Galagan et al., 2011b), Copyright 2010, Elsevier B.V.).

Processing on plastic foils such as PEN and PET typically is limited to temperatures generally below $100^{\circ} \mathrm{C}$. Thus, the quality of ITO layer is not optimal. First of all, this results in a higher sheet resistance of ITO on plastic substrates, as is shown above. Additionally, low temperature processing leads to an increased surface roughness compared to ITO annealed at higher temperatures as for ITO on glass. The ITO coated PET foil is typically characterized by the presence of a huge amount of spikes, which create unwanted shorts in the OPV devices. Fig. 8 depicts the AFM topology images of ITO on glass and ITO on PET foil. The current leakage due to shorts is indicated by the lower fill factor and decreased value of short circuit current.

Another disadvantage of TCO layers and ITO in particular, is their brittleness. The ITO anode has a critical bending radius of about $8 \mathrm{~mm}$, up to which the film can stand the load without increasing in resistance (Paetzold et al., 2003). However, the number of bending cycles, even with low bending radius, will affect the resistance of ITO. ITO breaks down rather quickly and shows an increase in resistance, which will negatively affect the performance of the organic solar cells. Furthermore, the limited availability of materials, such as indium, results in a high cost of ITO coatings. In (Krebs et al., 2010) it was estimated that the cost of typical commercial available PET/ITO substrates, used for roll-to-roll manufacturing of organic solar cells, takes more then half of the total material cost required for the manufacturing of OPV modules.

\subsection{ITO-free transparent electrode}

The biggest motivation for the development of organic solar cell technology is the low cost potential, based on the use of low-cost materials and substrates and the very high potential production speeds that can be reached by roll-to-roll printing and coating techniques 
(Medford et al., 2010; Krebs, 2009d; Krebs, 2009e; Krebs, 2009b; Galagan et al., 2011b; Blankenburg et al., 2009). However, indium-tin oxide (ITO), which is commonly used as a transparent electrode, is one of the main cost consuming elements in present photovoltaic devices (Krebs, 2009e; Krebs et al., 2010; Espinosa et al., 2011). The second argument to omit ITO from OPV devices is mechanical flexibility. The brittle ITO layer can be easily cracked, leading to a decrease in conductivity and as a result degradation of the device performance. A third argument is the multi-step patterning of the ITO layer which involves a lot of chemicals. A lot of efforts have been directed on the development of highly conductive polymeric materials such as poly(3,4-ethylenedioxythiophene):poly(4-styrene sulphonate) (PEDOT:PSS). Replacement of ITO by highly conductive PEDOT:PSS has been intensively investigated and reported (Zhou et al., 2009; Winther-Jensen \& Krebs, 2006; Hau et al., 2009; Chang et al., 2008; Ahlswede et al., 2008; Jun-Seok, 2011). However, organic photovoltaic devices with only a PEDOT:PSS electrode do not provide high efficiency for large area devices due to the limited conductivity of the PEDOT:PSS, which is typically up to $500 \mathrm{~S} / \mathrm{m}$. Increasing of the layer thickness can reduce the sheet resistance, but at the same time this decreases the transparency. Decreasing of the transparency has a negative influence on the short circuit current and results in efficiency losses (Hau et al., 2009). The JV curve of the 2 $\mathrm{cm}^{2}$ device with the high conductive PEDOT:PSS (HC-Pedot) as electrode is shown in Fig. 9. Such type of device is characterized by a low fill factor due to the limited conductivity of the PEDOT:PSS layer. The fill factor depends on the series resistance (Rs) of solar cells. Here, the high sheet resistance of the electrode may, therefore, reduce the fill factor. At the same time, the Voc does not change. The decreased Jsc can be partly explained by the very high value of the series resistance. Normally, Jsc does not change much with increasing of Rs, and only starts to change with very large values of Rs (Servaites et al., 2010), as in this case.

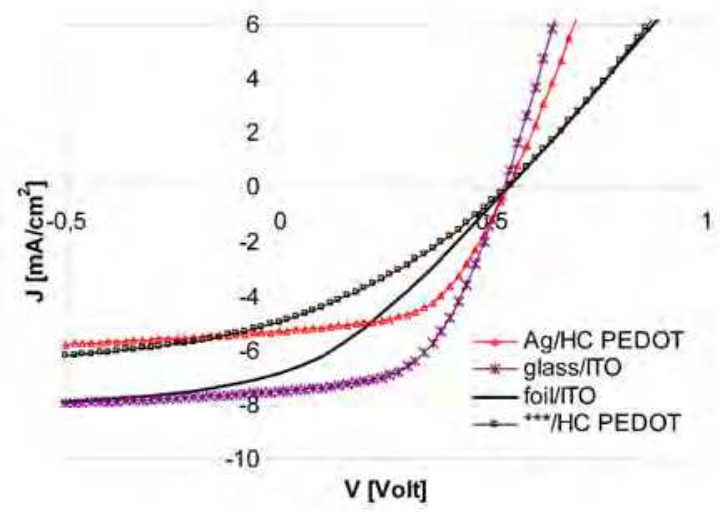

Fig. 9. JV-curves of OPV devices with an active area of $4 \mathrm{~cm}^{2}$ with different anodes: a) ITO on glass substrate, b) ITO on PEN/barrier substrate, c) high conductive Pedot on glass substrate and d) high conductive Pedot with metal grid on glass substrate.

Improving the conductivity of such polymeric electrode is possible by combining it with a metal grid, which is either thermally evaporated through micro structured shadow masks (Zimmermann et al., 2007; Glatthaar et al., 2005) or patterned by a lithographic method (Zou et al., 2010; Tvingstedt \& Inganäs, 2007). However, photolithography is a complex and time 
consuming multiple step process, which requires expensive facilities. Moreover, the photolithographic process generates large volume of hazardous waste. Vacuum deposition techniques for the fabrication of current collecting grids are not as costly as photolithography, but are energy intensive and give patterns with low resolution. Metal deposition by electroless plating is simpler than photolithography, but it is rather slow, environmentally undesirable as it creates a lot of waste. The deposition of an Ag grid by diffusion transfer reversal, which is a specific photographic technique, has been reported (Aernouts et al., 2004). This technique is fully compatible with large area roll-to-roll processing, yielding metallic conducting Ag-patterns on a plastic support. Another way of making grids is using laser ablation. However, this technique is not the best choice for the preparation of the grids due to low speed of the process, where more than $90 \%$ of the surface has to be removed. Additionally, debris formation will complicate preparation of thin organic solar cells. Printing of the metal grid, however, is a good alterative and a prerequisite for fully printed OPV devices, enabling low-cost manufacturing. Screen printed silver grids (Krebs, 2009d; Krebs et al., 2011) were demonstrated in a roll-to-roll processed inverted OPV device, where the grid is the last printed layer in the devices. Inkjet printed current collecting grids as a part of a composite anode in a conventional OPV device significantly improved efficiency of ITO-free devices with PEDOT based transparent electrodes (Fig. 9). In this case the grid is the first printed layer in the device (Galagan et al., 2010). Integration of a conductive grid significantly decreases the resistance of the polymer anode. Despite the fact that single pass inkjet printed current collection grids demonstrate a sheet resistance of $15 \Omega$ / for an grid area coverage of $7.2 \%$, which is still a high value for large area devices, but anyhow, it is better than what can be reached with ITO on a flexible substrate and comparable with ITO on glass. The conductivity of the grid can be improved by increasing the line height, but the increase in topology of the grid might make it impossible to overcoat the grid with the subsequent thin electro-active device layers.

a)

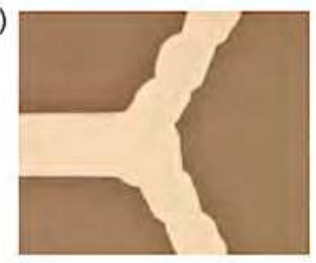

c)

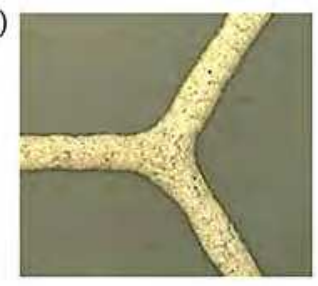

b)
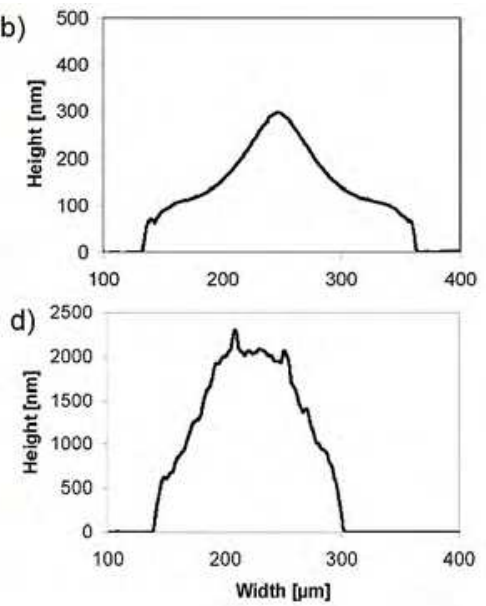

Fig. 10. a) 50x optical microscope image and b) typical line profile of inkjet printed silver lines (grid) on barrier coated PEN film. (c) 50x microscope image and (d) typical line profile of screen printed Inktec TEC-PA-010 ink (c and d reproduced with permission from (Galagan et al., 2011a), Copyright 2010, Elsevier B.V.). 
Integration of silver grids into the structure of organic solar cell, however, has some restrictions. Such silver grid covers a part of the surface, making this part non-transparent for light. That is why the surface coverage should be limited; another reason is the high price of Ag. Ink jet printed honeycombs grids with a pitch size of $5 \mathrm{~mm}$ and the set value of the line width of $100 \mu \mathrm{m}$, should provide a surface coverage of approximately $4 \%$. However, there is observed a mismatch in the theoretical and experimental values. Inkjet printed grids reported by (Galagan et al., 2010) have a mismatch geometry factor of 1.48. First of all, due to the bad pinning of the Ag ink on the receiving substrate (in this case the top layer of the barrier, $\mathrm{Si}_{\mathrm{x}} \mathrm{N}_{\mathrm{y}}$ ) the observed line width is $180 \mu \mathrm{m}$ instead of $100 \mu \mathrm{m}$. This increases the expected surface coverage from $4 \%$ to $7.2 \%$. Also, the measured sheet resistance of such grids is roughly a factor 2.4 higher than predicted. This can be partly explained by the amount of deposited ink which was factor 1.5 lower than expected and partly by the dependency of the line width on the resistivity (the thinner the lines, the higher the resistivity of printed conductive lines sintered at a given condition (time and temperature). The optical microscopic image and typical line profile of inkjet printed silver grid lines on barrier coated PEN film is shown in Fig. 10, a, b.

Further improvement of the device performance is possible with improving the conductivity of the grid, which is possible by applying a larger amount of silver without increasing the area coverage of the grid. With inkjet printing this is possible by using multi-pass printing. Another alternative is screen printing of the grids (Galagan et al., 2011a). Screen printing inks are more viscous, have higher content of solid material and as a result have higher lines profile (Fig. 10, c, d) and better conductivity. The effective line width of the screen printed grid lines is $160 \mu \mathrm{m}$ (although set at $100 \mu \mathrm{m}$ ) resulting in $6.4 \%$ area coverage instead of $4 \%$. The average printed line height was higher than expected $(1.5 \mu \mathrm{m}$ instead of $1 \mu \mathrm{m}$. After sintering, the grid showed a sheet resistance of $1 \Omega / \square$, which is in a very agreement with the theoretically expected value. The low value of Rs should be very efficient for larger area OPV devices. However, over-coating of the grid with PEDOT:PSS using spin coating was not successful due to the height of the lines. This problem was solved by embedding the grid in the barrier layer as shown in Fig. 11. In this way, a smooth surface, containing the current collecting grid, was obtained (See Fig. 11 c).
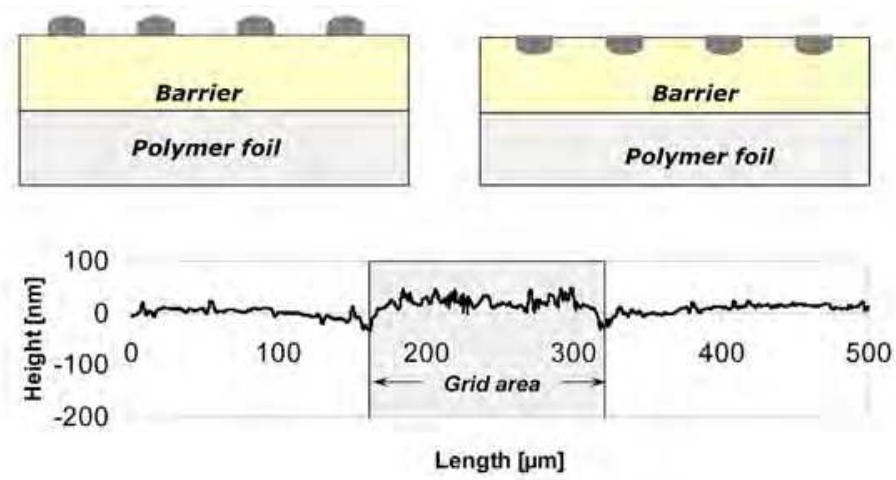

Fig. 11. Schematic illustration of current collection grids: (a) printed on top and (b) embedded into the barrier. (c) Dektak profile of the surface with embedded grid (reproduced with permission from (Galagan et al., 2011a), Copyright 2010, Elsevier B.V.). 

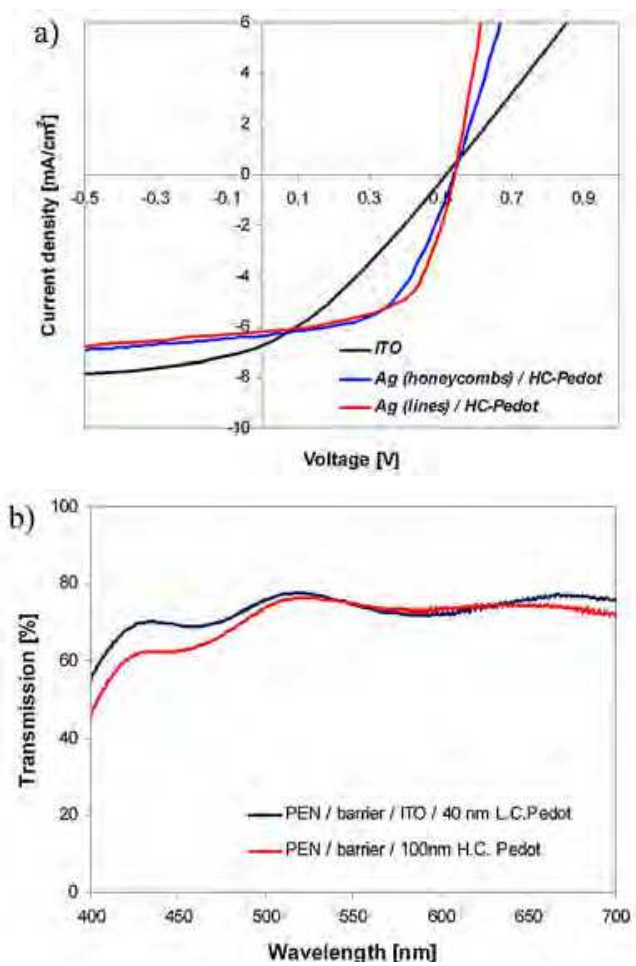

Fig. 12. a - JV-curves of flexible OPV devices with an active area of $4 \mathrm{~cm}^{2}$ with different anodes: (a) ITO on glass substrate, (b) and (c) high conductive PEDOT:PSS with, respectively, a honeycomb and a line pattern current collecting grid (reproduced with permission from (Galagan et al., 2011a), Copyright 2010, Elsevier B.V.); b - Transmittance of the device stacks: PEN/barrier/ITOwith40nmLC-PEDOT:PSS versus PEN/barrier/with 100 nm HC-PEDOT:PSS (reproduced with permission from (Galagan et al., 2011a), Copyright 2010, Elsevier B.V.).

The JV curves of the $2 \times 2 \mathrm{~cm}^{2}$ devices with embedded screen printed current collecting grids are shown in Fig. 12, a. The difference in current density for devices with such grids versus ITO-based devices can be partly explained by shadow losses due to the grids. With the honeycomb pattern, $6.4 \%$ of the surface is covered by the grid, while the line pattern covers $8 \%$ of the surface. This explains the difference in the $\mathrm{J}_{\mathrm{sc}}$ between two grid-based devices.

Apart from shadow losses by the grid, the transparency difference between the double layer ITO/low conductive PEDOT and the highly conductive PEDOT needs to be taken into account. The $120 \mathrm{~nm}$ layer of ITO on PEN provides an average transmittance of $90 \%$ over the visible spectrum $(400-700 \mathrm{~nm})$. The subsequent $40 \mathrm{~nm}$ layer of low conductive PEDOT also absorbs a part of the solar spectrum. The question now is: will this double layer yield lower or higher transparency compared to the $100 \mathrm{~nm}$ thick layer of the highly conductive PEDOT combined with a grid with a given area coverage? The transmission spectra of the stacks PEN/barrier/ITO/40 nm LC PEDOT and PEN/barrier/100 nm HC PEDOT are shown in Fig. 12, b. 
The transmission spectra indicate that the transmittance of the light into the photoactive layer is higher in case of the ITO based device. The $100 \mathrm{~nm}$ thick layer of high conductive Pedot has a relative high absorption in the visible region. Combined with a grid makes it only worse. This fact can partly explain the difference in the measured current in both types of devices. Also interference effects should be taking into account. The thickness of the active layer ( $220 \mathrm{~nm}$ ), according to optical modeling (Moule et al., 2006; Moulé \& Meerholz, 2007) was optimal for the ITO based devices with $40 \mathrm{~nm}$ thick PEDOT layer. Such ratio in the layer thicknesses provides a maximum value of Jsc. Omitting of ITO and replacement of low conductive Pedot by high conductive with a different layer thickness could cause the interference induced maximum Jsc to be shifted. Only additional modeling on the optimal thicknesses of the layers can help explaining these results further. Non-optimized layer thicknesses can also contribute to the slightly lower values of Jsc in ITO-free devices. Additionally, as already mentioned above, the shadow effect of the grids results in a lower current density in the ITO-free devices. The sum of all these factors explains why the current density in ITO-based and ITO-free devices is different. Further improvements of the current density in ITO-free devices are possible by decreasing the shadow effect (by minimizing the line width in the grids), by increasing the transparency of the high conductive PEDOT and by further optimization of layer thicknesses.

Solar cells containing the composite anode versus ITO-based devices show almost the same open-circuit voltage $\left(\mathrm{V}_{\mathrm{oc}}\right)$ values, but the fill factors significantly differ. Introduction of a conductive grid with a sheet resistance of $1 \Omega / \square$ into the photovoltaic devices substantially improves the fill factor for $2 \times 2 \mathrm{~cm}^{2}$ devices. As the HC-PEDOT is still responsible for the current collection in the area between the grid lines, the high conductivity of this PEDOT is very important. Moreover, the distance between the grid lines is an important parameter for successful current collection. In (Zimmermann et al., 2007) the optimum pitch size has been calculated in wrap-through OPV devices for PEDOT formulations with different conductivities. In (Galagan et al., 2011a) two different pitch sizes have been tested. The results illustrate that the device with the line pattern, with a pitch size of $2 \mathrm{~mm}$, has a higher fill factor that the honeycomb pattern, which has a pitch size of $5 \mathrm{~mm}$.

As the data show, replacing the ITO by a composite anode consisting of combination of a metal grid and HC-PEDOT, results in a significant increase in efficiency for devices of $2 \times 2$ $\mathrm{cm}^{2}$. Future work will concentrate in maximizing the cell area without substantial efficiency losses by using optimized grid structures. This will enable a substantial increase of the active area of OPV modules which in turn will increase the final $\mathrm{Wp} / \mathrm{m}^{2}$.

An additional and very significant argument to support the ITO-free approach with current collecting grids and high conducting PEDOT is the observed improved stability of such devices. In (Galagan et al., 2010) lifetimes of ITO based and ITO-free devices have been compared. A study of the intrinsic stability of the ITO-free devices and a comparison with the "standard" ITO-based devices has been performed on devices with the following layouts: "glass/Ag-grid/HC-Pedot/P3HT:PCBM/LiF/Al/metal encapsulation" and glass/ITO/Pedot/P3HT:PCBM/LiF/Al/metal encapsulation", respectively. Both types of devices were prepared on glass substrates, as glass provides good barrier properties from one side of the devices. The other side of the devices was protected by a stainless steel lid containng a getter material which was sealed by using epoxy glue. Identical sets of devices have been tested under three different conditions: in dark at room temperature, in dark at a 
temperature of $45^{\circ} \mathrm{C}$ and illuminated $\left(1.5 \mathrm{AM}\right.$ condition) at $45^{\circ} \mathrm{C}$. The cells, which were kept in the dark at room temperature, remained stable over time. At an elevated temperature in the dark, the efficiency of ITO-based devices drops. The efficiency of the ITO-free devices did not change substantially. The combination of light and elevated temperature shows a very rapid degradation of the ITO-based devices. At the same time the efficiency of the ITOfree devices remains almost unchanged. The relative changes of the $\mathrm{V}_{\mathrm{oc}}, \mathrm{J}_{\mathrm{sc}}, \mathrm{FF}$ and efficiency of the devices stored at $45^{\circ} \mathrm{C}$ under the light, are given in Fig. 13 .

Light and temperature are the two main factors which speed up the degradation of the solar cells. In the described experiment encapsulated devices were used. Due to the presence of a getter material and the quality of the sealant, leakage of water and oxygen from the environment does not play a significant role during the test period. All observed changes in the device performance are related to the intrinsic stability of the devices. It is clear that devices containing ITO degrade much faster than ITO-free devices. This fast degradation of ITO-based devices is explained by the indium diffusion through all layers in such devices (Jørgensen et al., 2008; Krebs \& Norrman, 2007). Indium migration results in conductivity losses in the ITO anode. These conductivity losses lead to an increase of the series resistances in the devices, and as a result the fill factor decreases. But it should be stated that for some ITO/PEDOT:PSS combinations, this degradation is not observed.
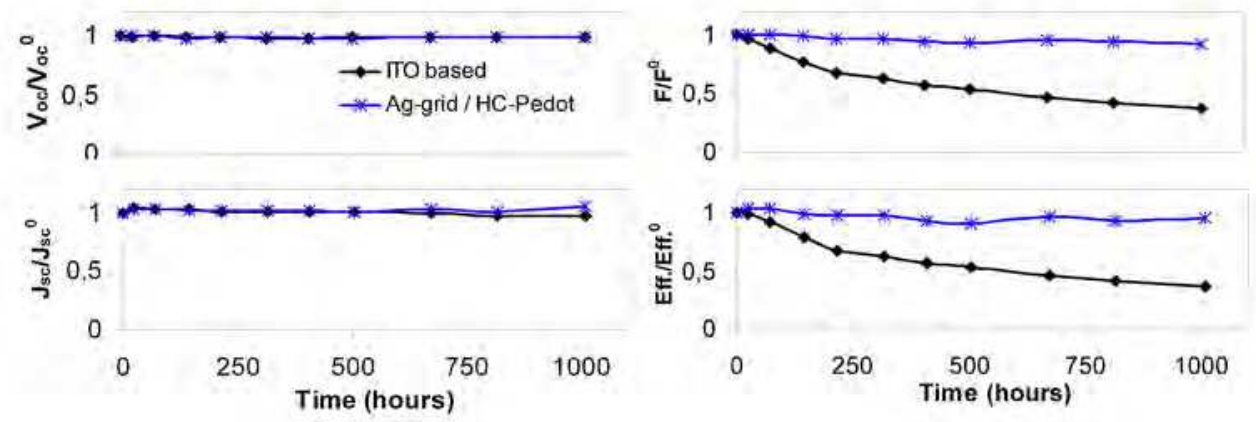

Fig. 13. Relative changes of the $\mathrm{V}_{\mathrm{oc}}, \mathrm{J}_{\mathrm{sc}}$, FF and efficiency of device over time, stored at $45^{\circ} \mathrm{C}$ with light exposure.

This work demonstrates the possibility of excluding the expensive and brittle ITO electrode from organic photovoltaic devices and replace it by a composite anode containing a combination of a printed metal grid and a printed high conducting PEDOT:PSS layer. This should enable complete roll-to-roll printing of solar cells on large flexible plastic substrates. Devices with a composite electrode illustrate a reasonable efficiency. Integration of conducting grids significantly decreases the resistance of the anode. Moreover, the observed intrinsic stability of studied ITO-free devices is much higher than the stability of studied devices based on ITO. After 1000 hours at elevated temperature and light exposure, the encapsulated ITO-free devices maintained more than $90 \%$ of their initial efficiency, whereas the efficiency of devices with an ITO electrode was reduced to $40 \%$ of their initial efficiency. In the end, taking into account the cost, compatibility and simplicity of roll-to-roll production of the patterned electrode, the devices with silver grids and highly conductive PEDOT:PSS are evidently preferred. 


\section{Module design and size}

A standard single organic solar cell has an open circuit voltage below $1 \mathrm{~V}$. In solar cells based on P3HT/PCBM blend this value is typical around $0.5 \mathrm{~V}$. The voltage at maximum power point is lower, even at high illumination level. The value of current strongly depends on the light intensity and the size of active area of the device. Scaling up of the active area can increase the actual output current, but the voltage delivered by photovoltaic device will remain unchanged. For electrical powering of electronic tools and devices, very often a much higher voltage is required. This can be achieved by serial interconnection of several single cells for delivering a higher voltage. The interconnection can be performed by external wiring, which is commonly used in wafer-based Si solar cells. However, application coating and printing techniques for manufacturing of solar cells creates the possibility of direct patterning of the layers. Patterned printing opens new possibilities of manufacturing solar sell modules with internal interconnection (Fig. 14). Printing of complete modules provides a significant potential to decrease the manufacturing cost and to increase the stability of the solar cell modules.

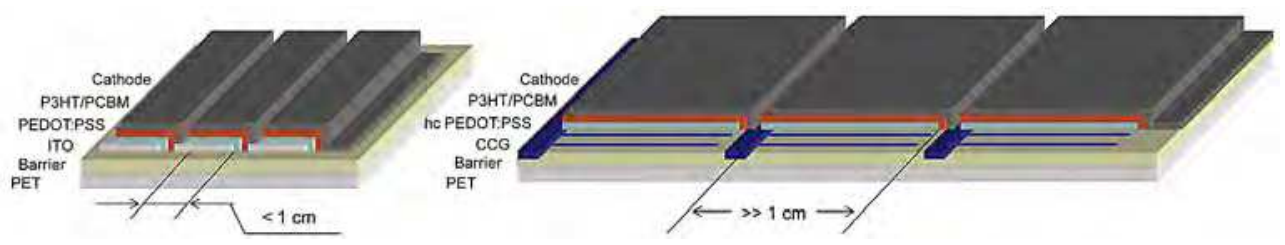

Fig. 14. a - Schematic illustration of the organic solar cell modules with ITO electrode and $\mathrm{b}$ - current collecting grids/high conducting PEDOT electrode.

As explained before, due to the relatively high sheet resistivity of ITO, the width of individual efficient cells typically is limited to $0.5-1 \mathrm{~cm}$. By this way the Ohmic losses are reduced. By serial interconnection of individual cells the total active area coverage of the module will be rather low as, certainly with printing techniques, the non-active interconnections will be in the same range, i.e. between $0.5-1 \mathrm{~cm}$. The larger the ratio between active cell area and interconnection area, the lower the losses are. Hence, for reducing the losses, minimizing of the interconnection area and increasing the active area of single cell are the focus points. The concept with the current collecting grids can provide cell widths much larger then $1 \mathrm{~cm}$ without a substantial decrease in efficiency. In such a way, the active area of the module can be significantly improved (Fig. 14, b). This is one more advantage of using a composite electrode with current collecting grids in stead of ITO or other TCO's.

\section{Conclusions}

Commercialization of organic photovoltaics is complicated as many parameters change when moving from lab scale manufacturing of devices towards low-cost, roll-to-roll manufacturing. . The main factors which have influence on the efficiency, stability, and cost of the final product of the devices are: solvent, layer thickness, deposition technique, drying time, thermal annealing, substrate, electrode roughness and sheet resistance, size, 
design and architecture of the solar cells. Omitting expensive materials, such as ITO, and the development of a technology that allows for solution processed (composite) transparent electrodes seems to be a large step towards low cost manufacturing. ITO-free electrodes not only significantly decrease the cost but also provide better scalability and higher stability of the organic photovoltaic devices. Selection of the right deposition technique for each electro-active layer can enable successful low-cost manufacturing of complete OPV modules. We built a knowledge base concerning the influence of different parameters and process conditions on the performance, cost and lifetime of polymer solar cells. All these parameters can be used as an input for further development of roll-to-roll manufacturing.

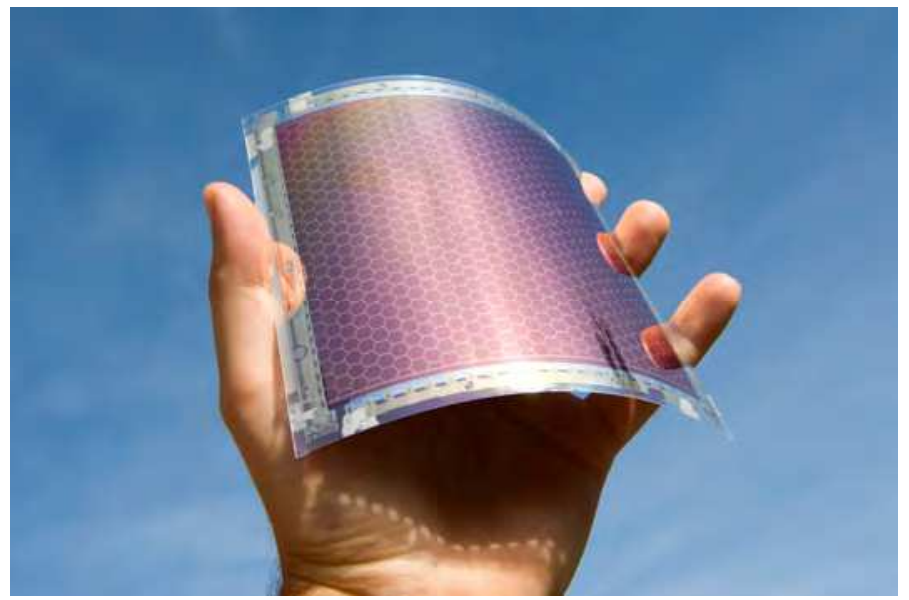

Fig. 15. ITO-free organic photovoltaic devices produced in Holst Centre $\left(15 \times 15 \mathrm{~cm}^{2}\right.$, active area is $\left.12 \times 12 \mathrm{~cm}^{2}\right)$.

\section{References}

Aernouts, T., Aleksandrov, T., Girotto, C., Genoe, J., \& Poortmans, J. 2008. Polymer based organic solar cells using ink-jet printed active layers. Applied Physics Letters, 92(3): 033306-3.

Aernouts, T., Vanlaeke, P., Geens, W., Poortmans, J., Heremans, P., Borghs, S., Mertens, R., Andriessen, R., \& Leenders, L. 2004. Printable anodes for flexible organic solar cell modules. Thin Solid Films, 451-452: 22-25.

Ahlswede, E., Muhleisen, W., Wahi, M. W. b. M., Hanisch, J., \& Powalla, M. 2008. Highly efficient organic solar cells with printable low-cost transparent contacts. Applied Physics Letters, 92(14): 143307.

Al-Ibrahim, M., Roth, H. K., \& Sensfuss, S. 2004. Efficient large-area polymer solar cells on flexible substrates. Applied Physics Letters, 85(9): 1481-1483.

Baek, W. H., Yang, H., Yoon, T. S., Kang, C. J., Lee, H. H., \& Kim, Y. S. 2009. Effect of P3HT:PCBM concentration in solvent on performances of organic solar cells. Solar Energy Materials and Solar Cells, 93(8): 1263-1267. 
Berson, S., De Bettignies, R., Bailly, S., \& Guillerez, S. 2007. Poly(3-hexylthiophene) Fibers for Photovoltaic Applications. Advanced Functional Materials, 17(8): 1377-1384.

Blankenburg, L., Schultheis, K., Schache, H., Sensfuss, S., \& Schrödner, M. 2009. Reel-to-reel wet coating as an efficient up-scaling technique for the production of bulkheterojunction polymer solar cells. Solar Energy Materials and Solar Cells, 93(4): 476483.

Brabec, C., Scherf, U., Dyakonov, V., \& (Ed(s).) 2008. Organic Photovoltaics: Materials, Device Physics, and Manufacturing Technologies, Wiley-VCH, ISBN 978-3527316755.

Chang, Y. M., Wang, L., \& Su, W. F. 2008. Polymer solar cells with poly(3,4ethylenedioxythiophene) as transparent anode. Organic Electronics, 9(6): 968-973.

Chang, Y. H., Tseng, S. R., Chen, C. Y., Meng, H. F., Chen, E. C., Horng, S. F., \& Hsu, C. S. 2009. Polymer solar cell by blade coating. Organic Electronics, 10(5): 741-746.

Colsmann, A., Stenzel, F., Balthasar, G., Do, H., \& Lemmer, U. 2009. Plasma patterning of Poly(3,4-ethylenedioxythiophene):Poly(styrenesulfonate) anodes for efficient polymer solar cells. Thin Solid Films, 517(5): 1750-1752.

Ding, J. M., de la Fuente Vornbrock, A., Ting, C., \& Subramanian, V. 2009. Patternable polymer bulk heterojunction photovoltaic cells on plastic by rotogravure printing. Solar Energy Materials and Solar Cells, 93(4): 459-464.

Eom, S. H., Senthilarasu, S., Uthirakumar, P., Hong, C. H., Lee, Y. S., Lim, J., Yoon, S. C., Lee, C., \& Lee, S. H. 2008. Preparation and characterization of nano-scale $\mathrm{ZnO}$ as a buffer layer for inkjet printing of silver cathode in polymer solar cells. Solar Energy Materials and Solar Cells, 92(5): 564-570.

Eom, S. H., Senthilarasu, S., Uthirakumar, P., Yoon, S. C., Lim, J., Lee, C., Lim, H. S., Lee, J., \& Lee, S. H. 2009. Polymer solar cells based on inkjet-printed PEDOT:PSS layer. Organic Electronics, 10(3): 536-542.

Espinosa, N., García -Valverde, R., Urbina, A., \& Krebs, F. C. 2011. A life cycle analysis of polymer solar cell modules prepared using roll-to-roll methods under ambient conditions. Solar Energy Materials and Solar Cells, 95(5): 1293-1302.

Galagan, Y., Rubingh, J. E., Andriessen, R., Fan, C. C., Blom, P., Veenstra, S. C., \& Kroon, J. M. 2011. ITO-free flexible organic solar cells with printed current collecting grids. Solar Energy Materials and Solar Cells, 95(5): 1339-1343.

Galagan, Y., Andriessen, R., Rubingh, E., Grossiord, N., Blom, P., Veenstra, S., Verhees, W., \& Kroon, J. 2010. Toward fully printed Organic Photovoltaics: Processing and Stability. Proceedings of Lope-C, 88-91, ISBN 978-3-00-029955-1.

Galagan, Y., de Vries, I. G., Langen, A. P., Andriessen, R., Verhees, W. J. H., Veenstra, S. C., \& Kroon, J. M. 2011b. Technology development for roll-to-roll production of organic photovoltaics. Chemical Engineering and Processing: Process Intensification, 50(5-6): 454-461.

Gamota, D. R., Brazis, P., Kalyanasundaram, K., \& Zhang, J. (Es(s.)) 2004. Printed Organic and Molecular Electronics, Springer, ISBN 978-1402077074.

Girotto, C., Moia, D., Rand, B. P., \& Heremans, P. 2011. High-performance organic solar cells with spray-coated hole-transport and active layers. Advanced Functional Materials, 21(1): 64-72.

Glatthaar, M., Niggemann, M., Zimmermann, B., Lewer, P., Riede, M., Hinsch, A., \& Luther, J. 2005. Organic solar cells using inverted layer sequence. Thin Solid Films, 491(1-2): 298-300. 
Green, R., Morfa, A., Ferguson, A. J., Kopidakis, N., Rumbles, G., \& Shaheen, S. E. 2008. Performance of bulk heterojunction photovoltaic devices prepared by airbrush spray deposition. Applied Physics Letters, 92(3): 033301-033303.

Gupta, D., Bag, M., \& Narayan, K. S. 2008. Area dependent efficiency of organic solar cells. Applied Physics Letters, 93(16): 163301-163303.

Hagemann, O., Bjerring, M., Nielsen, N. C., \& Krebs, F. C. 2008. All solution processed tandem polymer solar cells based on thermocleavable materials. Solar Energy Materials and Solar Cells, 92(11): 1327-1335.

Hau, S. K., Yip, H. L., Zou, J., \& Jen, A. K. Y. 2009. Indium tin oxide-free semi-transparent inverted polymer solar cells using conducting polymer as both bottom and top electrodes. Organic Electronics, 10(7): 1401-1407.

He, C., Germack, D. S., Joseph Kline, R., Delongchamp, D. M., Fischer, D. A., Snyder, C. R., Toney, M. F., Kushmerick, J. G., \& Richter, L. J. 2011. Influence of substrate on crystallization in polythiophene/fullerene blends. Solar Energy Materials and Solar Cells, 95(5): 1375-1381.

Hoppe, H. \& Sariciftci, N. S. 2006. Morphology of polymer/fullerene bulk heterojunction solar cells. Journal of Materials Chemistry, 16(1): 45-61.

Hoth, C. N., Choulis, S. A., Schilinsky, P., \& Brabec, C. J. 2007. High Photovoltaic Performance of Inkjet Printed Polymer:Fullerene Blends. Advanced Materials, 19(22): 3973-3978.

Hoth, C. N., Schilinsky, P., Choulis, S. A., \& Brabec, C. J. 2008. Printing Highly Efficient Organic Solar Cells. Nano Letters, 8(9): 2806-2813.

Hoth, C. N., Steim, R., Schilinsky, P., Choulis, S. A., Tedde, S. F., Hayden, O., \& Brabec, C. J. 2009. Topographical and morphological aspects of spray coated organic photovoltaics. Organic Electronics, 10(4): 587-593.

Hotta, S., Rughooputh, S. D. D. V., \& Heeger, A. J. 1987. Conducting polymer composites of soluble polythiophenes in polystyrene. Synthetic Metals, 22(1): 79-87.

Hsiao, Y. S., Chen, C. P., Chao, C. H., \& Whang, W. T. 2009. All-solution-processed inverted polymer solar cells on granular surface-nickelized polyimide. Organic Electronics, 10(4): 551-561.

Inganäs, O., Salaneck, W. R., Österholm, J. E., \& Laakso, J. 1988. Thermochromic and solvatochromic effects in poly(3-hexylthiophene). Synthetic Metals, 22(4): 395-406.

Ishikawa, T., Nakamura, M., Fujita, K., \& Tsutsui, T. 2004. Preparation of organic bulk heterojunction photovoltaic cells by evaporative spray deposition from ultradilute solution. Applied Physics Letters, 84(13): 2424-2426.

Jang, J., Seok-Soon, K., Seok-In, N., Byung-Kwan, Y., \& Dong-Yu, K. 2009. Time-Dependent Morphology Evolution by Annealing Processes on Polymer:Fullerene Blend Solar Cells. Advanced Functional Materials, 19(6): 866-874.

Janssen, G., Aguirre, A., Goovaerts, E., Vanlaeke, P., Poortmans, J., \& Manca, J. 2007. Optimization of morphology of P3HT/PCBM films for organic solar cells: effects of thermal treatments and spin coating solvents. Eur.Phys.J.Appl.Phys., 37(3): 287290.

Jørgensen, M., Norrman, K., \& Krebs, F. C. 2008. Stability/degradation of polymer solar cells. Solar Energy Materials and Solar Cells, 92(7): 686-714.

Jun-Seok, Y. 2011. Variations of cell performance in ITO-free organic solar cells with increasing cell areas. Semiconductor Science and Technology, 26(3): 034010. 
Kaihovirta, N. J., Tobjörk, D., Mäkelä, T., \& Österbacka, R. 2008. Low-Voltage Organic Transistors Fabricated Using Reverse Gravure Coating on Prepatterned Substrates. Advanced Engineering Materials, 10(7): 640-643.

Kawano, K., Sakai, J., Yahiro, M., \& Adachi, C. 2009. Effect of solvent on fabrication of active layers in organic solar cells based on poly(3-hexylthiophene) and fullerene derivatives. Solar Energy Materials and Solar Cells, 93(4): 514-518.

Kim, S. O., Chung, D. S., Cha, H., Hwang, M. C., Park, J. W., Kim, Y. H., Park, C. E., \& Kwon, S. K. 2011. Efficient polymer solar cells based on dialkoxynaphthalene and benzo[c][1,2,5]thiadiazole: A new approach for simple donor-acceptor pair. Solar Energy Materials and Solar Cells, 95(7): 1678-1685.

Kopola, P., Aernouts, T., Guillerez, S., Jin, H., Tuomikoski, M., Maaninen, A., \& Hast, J. 2010. High efficient plastic solar cells fabricated with a high-throughput gravure printing method. Solar Energy Materials and Solar Cells, 94(10): 1673-1680.

Kopola, P., Aernouts, T., Sliz, R., Guillerez, S., Ylikunnari, M., Cheyns, D., VSlimSki, M., Tuomikoski, M., Hast, J., Jabbour, G., MyllylS, R., \& Maaninen, A. 2011. Gravure printed flexible organic photovoltaic modules. Solar Energy Materials and Solar Cells, 95(5): 1344-1347.

Koppe, M., Brabec, C. J., Heiml, S., Schausberger, A., Duffy, W., Heeney, M., \& McCulloch, I. 2009. Influence of Molecular Weight Distribution on the Gelation of P3HT and Its Impact on the Photovoltaic Performance. Macromolecules, 42(13): 4661-4666.

Krebs, F. C., Tromholt, T., \& Jørgensen, M. 2010. Upscaling of polymer solar cell fabrication using full roll-to-roll processing. Nanoscale, 2(6): 873-886.

Krebs, F. C. 2009b. Fabrication and processing of polymer solar cells: A review of printing and coating techniques. Solar Energy Materials and Solar Cells, 93(4): 394-412.

Krebs, F. C. 2009c. Pad printing as a film forming technique for polymer solar cells. Solar Energy Materials and Solar Cells, 93(4): 484-490.

Krebs, F. C. 2009a. All solution roll-to-roll processed polymer solar cells free from indiumtin-oxide and vacuum coating steps. Organic Electronics, 10(5): 761-768.

Krebs, F. C. 2009d. Polymer solar cell modules prepared using roll-to-roll methods: Knifeover-edge coating, slot-die coating and screen printing. Solar Energy Materials and Solar Cells, 93(4): 465-475.

Krebs, F. C. 2009e. Roll-to-roll fabrication of monolithic large-area polymer solar cells free from indium-tin-oxide. Solar Energy Materials and Solar Cells, 93(9): 1636-1641.

Krebs, F. C., Alstrup, J., Spanggaard , H., Larsen, K., \& Kold, E. 2004. Production of largearea polymer solar cells by industrial silk screen printing, lifetime considerations and lamination with polyethyleneterephthalate. Solar Energy Materials and Solar Cells, 83(2-3): 293-300.

Krebs, F. C., Gevorgyan, S. A., \& Alstrup, J. 2009. A roll-to-roll process to flexible polymer solar cells: model studies, manufacture and operational stability studies. Journal of Materials Chemistry, 19(30): 5442-5451.

Krebs, F. C., Jørgensen, M., Norrman, K., Hagemann, O., Alstrup, J., Nielsen, T. D., Fyenbo, J., Larsen, K., \& Kristensen, J. 2009. A complete process for production of flexible large area polymer solar cells entirely using screen printing--First public demonstration. Solar Energy Materials and Solar Cells, 93(4): 422-441. 
Krebs, F. C. \& Norrman, K. 2010. Using Light-Induced Thermocleavage in a Roll-to-Roll Process for Polymer Solar Cells. ACS Applied Materials E Interfaces, 2(3): 877-887.

Krebs, F. C. \& Norrman, K. 2007. Analysis of the failure mechanism for a stable organic photovoltaic during $10000 \mathrm{~h}$ of testing. Progress in Photovoltaics: Research and Applications, 15(8): 697-712.

Krebs, F. C., Spanggard, H., Kjær, T., Biancardo, M., \& Alstrup, J. 2007. Large area plastic solar cell modules. Materials Science and Engineering: B, 138(2): 106-111.

Krebs, F. C., Søndergaard, R., \& Jørgensen, M. 2011. Printed metal back electrodes for R2R fabricated polymer solar cells studied using the LBIC technique. Solar Energy Materials and Solar Cells, 95(5): 1348-1353.

Lawrence, D., Kohler, J., Brollier, B., Claypole, T., \& Burgin, T. 2004. Manufacturing platforms for Printing Organic Circuit. In Printed organic and molecular electronics, Gamota D. R., Brazis P., Kalyanasundaram K. \& Zhang J. (Eds.), 161-346. Kluwer Academic Publishers, ISBN 978-1402077074.

Lim, Y. F., Lee, J. K., Zakhidov, A. A., DeFranco, J. A., Fong, H. H., Taylor, P. G., Ober, C. K., \& Malliaras, G. G. 2009. High voltage polymer solar cell patterned with photolithography. Journal of Materials Chemistry, 19(30): 5394-5397.

Lungenschmied, C., Dennler, G., Neugebauer, H., Sariciftci, S. N., Glatthaar, M., Meyer, T., \& Meyer, A. 2007. Flexible, long-lived, large-area, organic solar cells. Solar Energy Materials and Solar Cells, 91(5): 379-384.

Malik, S., Jana, T., \& Nandi, A. K. 2001. Thermoreversible Gelation of Regioregular Poly(3hexylthiophene) in Xylene. Macromolecules, 34(2): 275-282.

Manceau, M., Angmo, D., Jørgensen, M., \& Krebs, F. C. 2011. ITO-free flexible polymer solar cells: From small model devices to roll-to-roll processed large modules. Organic Electronics, 12(4): 566-574.

Manor, A., Katz, E. A., Tromholt, T., Hirsch, B., \& Krebs, F. C. 2011. Origin of size effect on efficiency of organic photovoltaics. Journal of Applied Physics, 109(7).

Medford, A. J., Lilliedal, M. R., Jørgensen, M., Aarø, D., Pakalski, H., Fyenbo, J., \& Krebs, F. C. 2010. Grid-connected polymer solar panels: initial considerations of cost, lifetime, and practicality. Opt.Express, 18(S3): A272-A285.

Ming-Yi, Lin, Chun-Yu, Lee, Shu-Chia, Shiu, Jen-Yu, Sun, Yu-Hong, Lin, Wen-Hau, Wu, and Ching-Fuh, Lin. (2010). All-solution-processed-inverted polymer solar cells on PET substrates with $\mathrm{CuOx}$ thin film as an anode interlayer. Proceedings of Photovoltaic Specialists Conference (PVSC), 35th IEEE., 001648-001649. ISBN/ISSN 0160-8371. June 2010.

Moulé, A. J. \& Meerholz, K. 2007. Minimizing optical losses in bulk heterojunction polymer solar cells. Applied Physics B: Lasers and Optics, 86(4): 721-727.

Moule, A. J., Bonekamp, J. B., \& Meerholz, K. 2006. The effect of active layer thickness and composition on the performance of bulk-heterojunction solar cells. Journal of Applied Physics, 100(9): 094503-094507.

Paetzold, R., Heuser, K., Henseler, D., Roeger, S., Wittmann, G., \& Winnacker, A. 2003. Performance of flexible polymeric light-emitting diodes under bending conditions. Applied Physics Letters, 82(19): 3342-3344.

Park, S. Y., Kang, Y. J., Lee, S., Kim, D. G., Kim, J. K., Kim, J. H., \& Kang, J. W. 2011. Spraycoated organic solar cells with large-area of $12.25 \mathrm{~cm}^{2}$. Solar Energy Materials and Solar Cells, 95(3): 852-855. 
Schilinsky, P., Waldauf, C., \& Brabec, C. J. 2006. Performance Analysis of Printed Bulk Heterojunction Solar Cells. Advanced Functional Materials, 16(13): 1669-1672.

Servaites, J. D., Yeganeh, S., Marks, T. J., \& Ratner, M. A. 2010. Efficiency Enhancement in Organic Photovoltaic Cells: Consequences of Optimizing Series Resistance. Advanced Functional Materials, 20(1): 97-104.

Shaheen, S. E., Radspinner, R., Peyghambarian, N., \& Jabbour, G. E. 2001. Fabrication of bulk heterojunction plastic solar cells by screen printing. Applied Physics Letters, 79(18): 2996-2998.

Steirer, K. X., Berry, J. J., Reese, M. O., van Hest, M. F. A. M., Miedaner, A., Liberatore, M. W., Collins, R. T., \& Ginley, D. S. 2009. Ultrasonically sprayed and inkjet printed thin film electrodes for organic solar cells. Thin Solid Films, 517(8): 27812786.

Susanna, G., Salamandra, L., Brown, T. M., Di Carlo, A., Brunetti, F., \& Reale, A. 2011. Airbrush spray-coating of polymer bulk-heterojunction solar cells. Solar Energy Materials and Solar Cells, 95(7): 1775-1778.

Tvingstedt, K. \& Inganäs, O. 2007. Electrode Grids for ITO Free Organic Photovoltaic Devices. Advanced Materials, 19(19): 2893-2897.

Vak, D., Kim, S. S., Jo, J., Oh, S. H., Na, S. I., Kim, J., \& Kim, D. Y. 2007. Fabrication of organic bulk heterojunction solar cells by a spray deposition method for low-cost power generation. Applied Physics Letters, 91(8): 081102-081103.

Voigt, M. M., Guite, A., Chung, D. Y., Khan, R. U. A., Campbell, A. J., Bradley, D. D. C., Meng, F., Steinke, J. H. G., Tierney, S., McCulloch, I., Penxten, H., Lutsen, L., Douheret, O., Manca, J., Brokmann, U., Sönnichsen, K., Hülsenberg, D., Bock, W., Barron, C., Blanckaert, N., Springer, S., Grupp, J., \& Mosley, A. 2010. Polymer FieldEffect Transistors Fabricated by the Sequential Gravure Printing of Polythiophene, Two Insulator Layers, and a Metal Ink Gate. Advanced Functional Materials, 20(2): 239-246.

Voigt, M. M., Mackenzie, R. C. I., Yau, C. P., Atienzar, P., Dane, J., Keivanidis, P. E., Bradley, D. D. C., \& Nelson, J. 2011. Gravure printing for three subsequent solar cell layers of inverted structures on flexible substrates. Solar Energy Materials and Solar Cells, 95(2): 731-734.

Winther-Jensen, B. \& Krebs, F. C. 2006. High-conductivity large-area semi-transparent electrodes for polymer photovoltaics by silk screen printing and vapour-phase deposition. Solar Energy Materials and Solar Cells, 90(2): 123-132.

Zhao, J., Swinnen, A., Van Assche, G., Manca, J., Vanderzande, D., \& Mele, B. V. 2009. Phase Diagram of P3HT/PCBM Blends and Its Implication for the Stability of Morphology. The Journal of Physical Chemistry B, 113(6): 1587-1591.

Zhou, Y., Li, F., Barrau, S., Tian, W., Inganäs, O., \& Zhang, F. 2009. Inverted and transparent polymer solar cells prepared with vacuum-free processing. Solar Energy Materials and Solar Cells, 93(4): 497-500.

Zimmermann, B., Glatthaar, M., Niggemann, M., Riede, M. K., Hinsch, A., \& Gombert, A. 2007. ITO-free wrap through organic solar cells--A module concept for costefficient reel-to-reel production. Solar Energy Materials and Solar Cells, 91(5): 374378. 
Zimmermann, B., Schleiermacher, H. F., Niggemann, M., \& Würfel, U. 2011. ITO-free flexible inverted organic solar cell modules with high fill factor prepared by slot die coating. Solar Energy Materials and Solar Cells, 95(7): 1587-1589.

Zou, J., Yip, H. L., Hau, S. K., \& Jen, A. K. Y. 2010. Metal grid/conducting polymer hybrid transparent electrode for inverted polymer solar cells. Applied Physics Letters, 96(20): 203301-203303. 


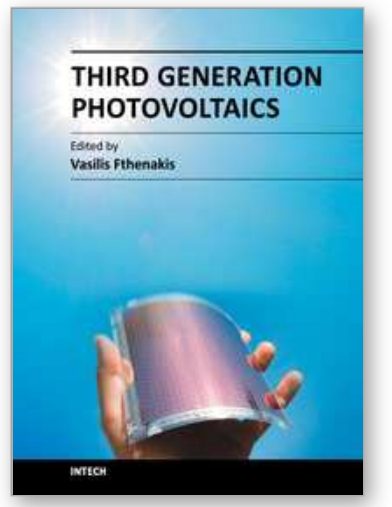

\author{
Third Generation Photovoltaics \\ Edited by Dr. Vasilis Fthenakis
}

ISBN 978-953-51-0304-2

Hard cover, 232 pages

Publisher InTech

Published online 16, March, 2012

Published in print edition March, 2012

Photovoltaics have started replacing fossil fuels as major energy generation roadmaps, targeting higher efficiencies and/or lower costs are aggressively pursued to bring PV to cost parity with grid electricity. Third generation PV technologies may overcome the fundamental limitations of photon to electron conversion in single-junction devices and, thus, improve both their efficiency and cost. This book presents notable advances in these technologies, namely organic cells and nanostructures, dye-sensitized cells and multijunction III/V cells. The following topics are addressed: Solar spectrum conversion for photovoltaics using nanoparticles; multiscale modeling of heterojunctions in organic PV; technologies and manufacturing of OPV; life cycle assessment of OPV; new materials and architectures for dye-sensitized solar cells; advances of concentrating $\mathrm{PV}$; modeling doped III/V alloys; polymeric films for lowering the cost of PV, and field performance factors. A panel of acclaimed PV professionals contributed these topics, compiling the state of knowledge for advancing this new generation of PV.

\title{
How to reference
}

In order to correctly reference this scholarly work, feel free to copy and paste the following:

Yulia Galagan and Ronn Andriessen (2012). Organic Photovoltaics: Technologies and Manufacturing, Third Generation Photovoltaics, Dr. Vasilis Fthenakis (Ed.), ISBN: 978-953-51-0304-2, InTech, Available from: http://www.intechopen.com/books/third-generation-photovoltaics/organic-photovoltaics-technologies-andmanufacturing

\section{INTECH}

open science | open minds

\section{InTech Europe}

University Campus STeP Ri

Slavka Krautzeka 83/A

51000 Rijeka, Croatia

Phone: +385 (51) 770447

Fax: +385 (51) 686166

www.intechopen.com

\section{InTech China}

Unit 405, Office Block, Hotel Equatorial Shanghai

No.65, Yan An Road (West), Shanghai, 200040, China

中国上海市延安西路65号上海国际贵都大饭店办公楼 405 单元

Phone: +86-21-62489820

Fax: $+86-21-62489821$ 
(C) 2012 The Author(s). Licensee IntechOpen. This is an open access article distributed under the terms of the Creative Commons Attribution 3.0 License, which permits unrestricted use, distribution, and reproduction in any medium, provided the original work is properly cited. 